\title{
Computational Models for the Structural Crashworthiness Analysis of a Fixed-Type Offshore Platform in Collisions with an Offshore Supply Vessel
}

\author{
M.P. Mujeeb-Ahmed ${ }^{\mathrm{a}, \mathrm{b}}$, Serdar Turgut Ince ${ }^{\mathrm{c}}$ and Jeom Kee Paik Pa,b $^{\mathrm{a}, \mathrm{d}}$ \\ ${ }^{a}$ The Korea Ship and Offshore Research Institute (The Lloyd's Register Foundation \\ Research Centre of Excellence), Pusan National University, Busan, South Korea \\ b Department of Naval Architecture and Ocean Engineering, Pusan National \\ University, Busan, South Korea \\ ${ }^{c}$ Department of Naval Architecture and Marine Engineering, Yildiz Technical \\ University, Istanbul, Turkey \\ ${ }^{\mathrm{d}}$ Department of Mechanical Engineering, University College London, London, UK \\ Corresponding author. J.K. Paik, Department of Mechanical Engineering, \\ University College London, London, UK. E-mail: j.paik@ucl.ac.uk.
}

\begin{abstract}
The aim of this paper was to develop practical modelling techniques for the structural crashworthiness analysis in collisions between a fixed-type offshore platform and an offshore supply vessel (OSV). The computational models used nonlinear finite element method involving large deformations (strains) of both vessel and offshore platform, dynamic effects of material (e.g., strain rate and dynamic fracture strain), and the influence of surrounding waters. The applicability of the modelling techniques was demonstrated with an applied example to collisions between an OSV and a jacket-type offshore platform, where a sensitivity analysis was carried out for different collision parameters (e.g., collision velocities and impact locations). It is concluded that the computational models can ultimately be employed for quantitative risk assessment of fixed-type offshore structures collided with an OSV, which requires to perform the structural crashworthiness analysis.
\end{abstract}

Keywords: Fixed-type offshore structures, offshore supply vessel, collisions, structural crashworthiness, jacket-type offshore platform, nonlinear finite element method (NLFEM), Quantitative collision risk assessment and management

\section{Nomenclature}

$b=$ plate breadth between support members

$C, q=$ Cowper-Symonds coefficients

$D=$ diameter of the tubular member

$d$ = diameter of the brace

$E=$ modulus of elasticity

$F_{d}=$ denting force 
$H=$ half-fold length of the plate element

$m_{p}=$ plastic moment capacity of the tube wall

$N=$ compressive or tensile force

$N_{p}=$ plastic yield stress in tension

$s$ = mesh size

$T=$ tube wall thickness of the column

$t=$ tube wall thickness of the brace / plate wall thickness / time

$V_{0}=$ collision velocity

$\gamma_{1}=$ factor associated with the mesh size

$\gamma_{2}=$ knock-down or correlation factor

$\delta_{d}=$ dent depth

$\varepsilon=$ strain

$\dot{\varepsilon}=$ strain rate

$\varepsilon_{e q}=$ equivalent maximum tensile strain

$\varepsilon_{f}=$ static fracture strain

$\varepsilon_{f c}=$ critical fracture strain

$\varepsilon_{f d}=$ dynamic fracture strain

$\xi=$ ratio of the static and dynamic energies absorbed

$\rho=$ density of the steel

$v=$ Poisson's ratio

$\sigma_{Y}=$ yield stress

$\sigma_{Y d}=$ dynamic yield stress

\section{Introduction}

Offshore supply vessels (OSVs) regularly visit offshore jacket platforms to transport supplies such as food, equipment, and chemicals. In the past, several minor or major collisions between supply vessels and offshore platforms have been reportedly recorded, as shown in Fig.1. Obviously, the platforms should be designed so that the safety should be sufficient enough with tolerance against such potential accidents. Structural consequences due to collisions involve highly complex and nonlinear 
failure mechanisms involving local denting, crushing, fracture, and permanent deformation [1].

(a)

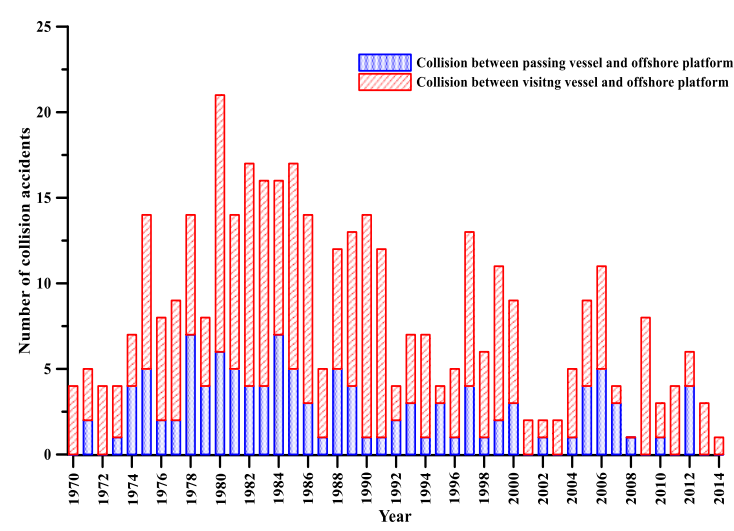

(b)

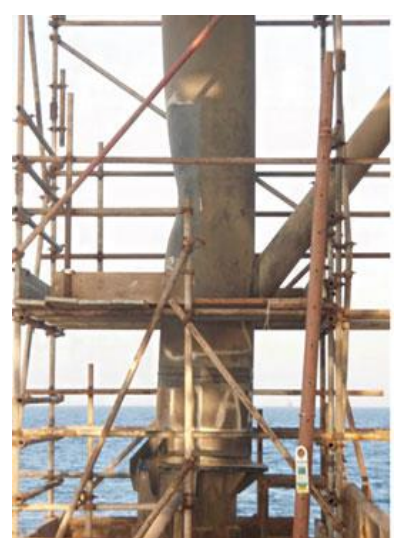

(c)
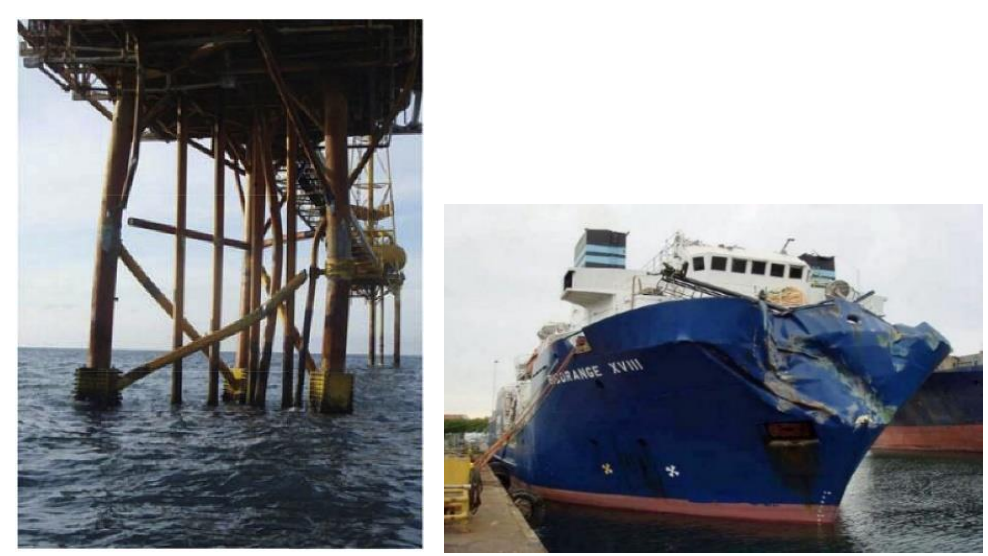

Fig. 1. Visiting vessel collision accidents to offshore installations: (a) annual distribution of collision accidents recorded for all offshore platforms during 1970-2014 [2], (b) supply vessel-wellhead platform collision [3], (c) Big Orange XVIII- Ekofisk 2/4-W platform collision [4].

Within the framework of quantitative risk assessment and management, one is asked to carry out the structural crashworthiness analysis at numerous collision scenarios, where the accuracy of resulting computations must be secured. As the structural responses are highly nonlinear associated with multiple physical processes and multiple criteria, a careful application of modelling techniques is required to capture realistic collision characteristics using numerical analyses such as nonlinear finite element analysis (NLFEA) software.

Numerous researches on ship collisions to offshore structures are available in the literature [5]. The structural responses of both striking and struck bodies closely correlate, as shown in Fig. 2 [6]. Based on the collision energy interaction between the ship and offshore platform, DNV GL [7] classified numerical analysis of a collision scenario into three design domains - ductile, shared-energy, and strength design, see Fig. 2(a), and suggested that the ship-platform collision falls in the ductile design 
region, where the striking vessel can be conservatively assumed rigid so that the analysis can be greatly simplified.

(a)

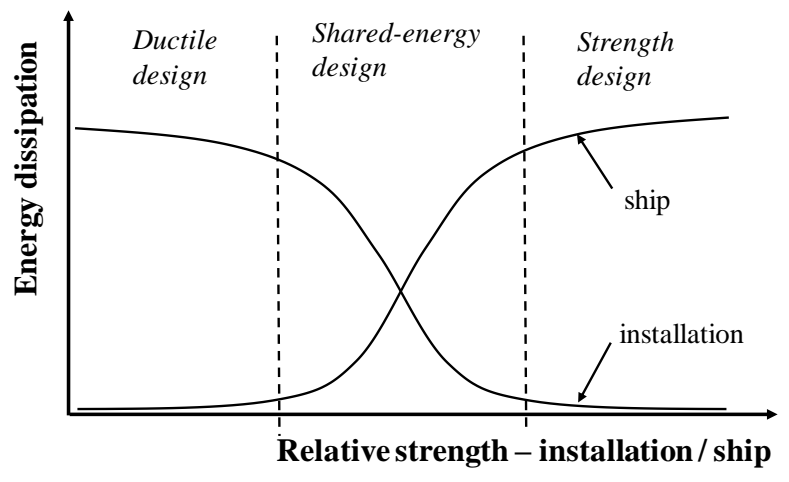

(b)

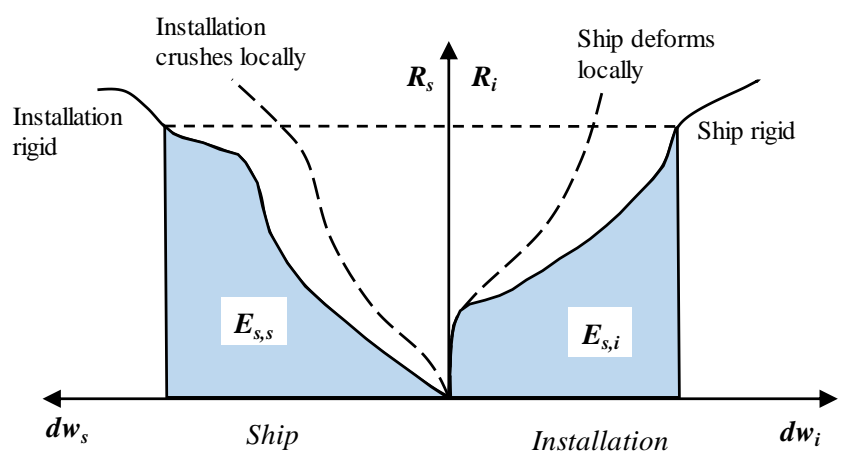

Fig. 2. (a) Classification of design domains [7], (b) Correlations of structural responses between striking and struck bodies.

However, Storheim and Amdahl [8] pointed out that simplifying the analysis by treating the ship as infinitely rigid may prove to be overly conservative, especially for collisions involving high levels of impact energy. Moreover, with the introduction of the modern supply vessels of increased size, and new bow shapes for operations in deep and ultra-deepwater offshore operations, the relative strength of the ship to offshore platform becomes comparable. Furthermore, the ship absorbs considerable impact energy through failure mechanisms such as plasticity, large deformations, and rupture of plate and stiffener components. A typical example could be the collision accident between Big Orange XVIII and the Ekofisk platform, where significant damage was caused to the platform as well as the vessel's bow structure, see Fig. 1(c). In reality, there exist no definite limits of relative strength, which could differentiate the three design domains, and one should pay attention to the deformations in both ship and offshore platforms to understand real collision behaviour, see Fig. 2(b).

DNV GL $[9,10]$ provided some specific guidelines and general requirements for the determination of structural capacity using NLFEA. Many researchers have performed the structural response analysis of individual tubular members against ship impacts, for instance [11-15]. Notaro et al. [16] performed the numerical analysis of OSV collision to a fixed offshore structure, considering both bodies as deformable. In general, the applicability of simplified analytical expressions depends on a particular 
class of load, boundary conditions, shape and size of the striking body, material properties, contact areas, etc. Most of the physical model tests were conducted on single tubular members with mid-span impact, fixed boundary conditions, rigid intender, and concentrated load. In reality, however, ship and offshore structures are large, and the collision is often eccentric, with multiple interactions between ship and tubular members combined with finite boundary stiffness at interconnected tubular members. Moreover, the collision interaction occurs under the influence of surrounding waters.

With the advancement of high-performance computers and the availability of sophisticated software, it has been realised that NLFEA is one of the powerful tools, especially for the analysis of large displacements involving geometric and material nonlinearities. However, research on numerical analysis considering such nonlinearities associated with dynamic fracture strain, structural deformation in both ship and platform, and hydrodynamic modelling with application to a full-scale model of a jacket platform is seldom available in the literature.

This paper aims to develop advanced computational modelling techniques in association with structural crashworthiness analysis of fixed-type offshore platforms in collisions with offshore supply vessels (OSV). A demonstration of the developed modelling techniques is shown with an illustrative example in collisions between a four-legged jacket-type offshore platform and a modern OSV. LS-DYNA software with an explicit finite element solver is used to conduct NLFEA [17]. The computational models take into account the effects of the interaction between striking ship and struck platform, material strain rate and dynamic fracture strain, surrounding water, and contact problem between two colliding bodies. A comparison of the results with analytical and recommended design load-deformation curves is made. A sensitivity study using the developed modelling techniques is also conducted to investigate the effects of collision load parameters on the structural damage.

\section{Procedure for structural crashworthiness analysis}

Figure 3 shows a flow chart of the structural crashworthiness analysis for collisions between an offshore platform and an offshore supply vessel. The numerical analysis begins with the definition of a collision event, which includes the characterisation of structural topologies, such as the target structures, environmental, and operational conditions.

Within the framework of quantitative collision risk assessment and management, a number of collision scenarios are selected in a probabilistic manner [1]. Mujeeb-Ahmed and Paik [2,18] describe the details of the probabilistic selection of collision scenarios between a jacket type offshore platform and an offshore supply vessel. The computational models for the structural crashworthiness analysis are formulated in association with each of individual collision scenarios so selected. Details of structural modelling techniques are addressed with an illustrative example of a collision accident between a jacket type offshore platform and an offshore supply vessel in the next section. 


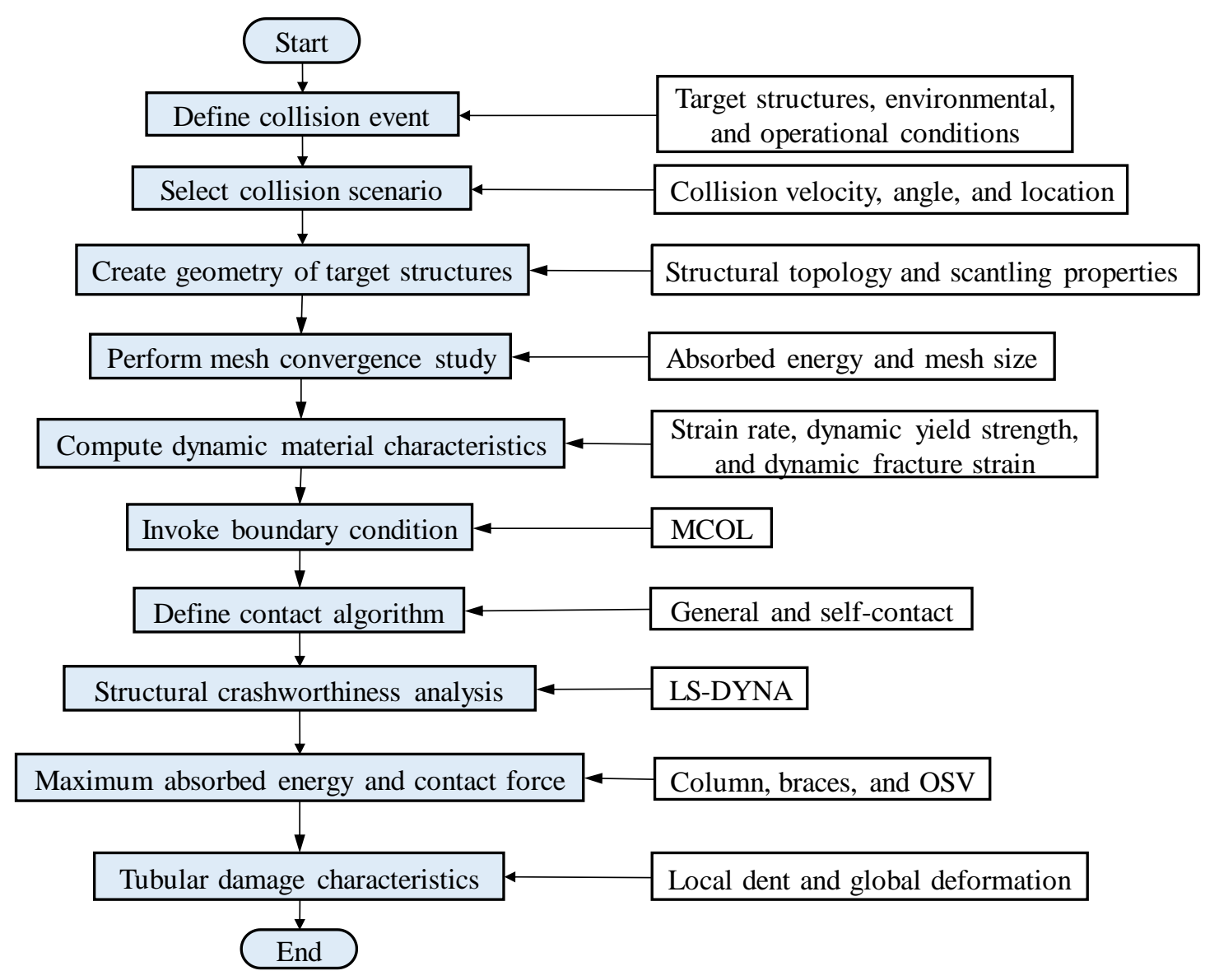

Fig. 3. Procedure for the structural crashworthiness analysis in collisions between an offshore platform and an offshore supply vessel.

\section{Computational models with an illustrative example}

\subsection{Details of target structures}

An illustrative example is considered where a modern OSV with a mass of 8,546 ton collides with a hypothetical four-legged jacket-type offshore platform installed at a water depth of $120 \mathrm{~m}$. Figure 4 shows the front and top views of the jacket platform, where the brace configurations are made of both horizontal and X-configured diagonal tubular members. The thickness of the leg and brace parts are selected in compliance with API [19] compactness criteria, i.e., $9000 / \sigma_{Y}<D / t<15200 / \sigma_{Y}$, where

$\sigma_{Y}$ is the yield stress of material in MPa. Table 1 provides the principal dimensions of the target structures.

The jacket substructure is composed of numerous brace and column members. To distinguish the damaged members during a collision scenario with ease, the members were given an identification number (ID). As illustrated in Fig. 5, the braces are categorised into horizontal, left-sided, and right-sided, along with the scantling properties of members around mean sea level (MSL). In this paper, the gravity loads 
due to the self-weight of the jacket and topside weight are not considered because the effect of gravity loads on impact responses prove to be negligible as studied by Travanca and Hao [13]. Besides, the preloading of the tubular members due to self-weight has a negligible effect on peak force-deformation curves, based on the series of numerical tests conducted for different tube dimensions [13]. Moreover, the collision of OSV is governed by low-velocity impact events, and the collision often occurs in the splash zone of the jacket platform.

(a)

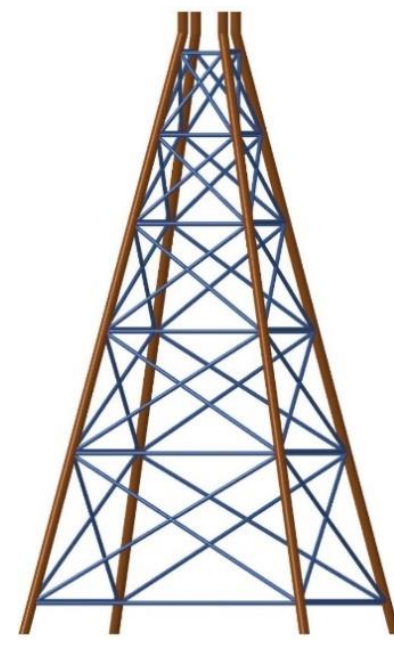

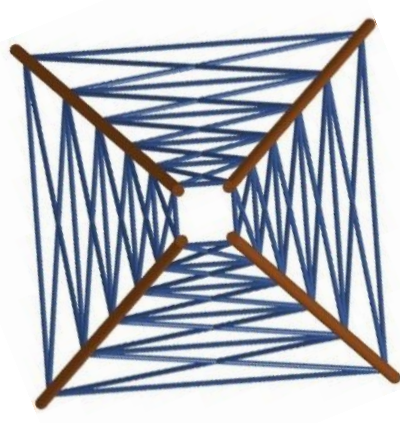

(b)

Fig. 4. Four-legged offshore jacket platform: substructure segment consisting of columns and braces: (a) front view, (b) top view.

Table 1. Principal characteristics of target offshore structures.

\begin{tabular}{llll}
\hline Platform particulars & Value & OSV particulars & Value \\
\hline Total height & $148 \mathrm{~m}$ & Overall length, $L_{O A}$ & $99.71 \mathrm{~m}$ \\
& & & \\
Freeboard & $20 \mathrm{~m}$ & Beam, $B$ & $23.25 \mathrm{~m}$ \\
Brace diameter, $d$ & $1 \mathrm{~m}$ & Draft, $\Delta$ & $7.1 \mathrm{~m}$ \\
Brace wall thickness, $t$ & $0.03 \mathrm{~m}$ & Displacement & 8546 tons \\
Leg diameter, $D$ & $2 \mathrm{~m}$ & Longitudinal radius of & $8.16 \mathrm{~m}$ \\
& & gyration, $K_{X X}$ & \\
Leg batter & $1: 7$ & Transverse radius of & $25 \mathrm{~m}$ \\
& & gyration, $K_{Y Y}$ & \\
Leg wall thickness, $T$ & $0.06 \mathrm{~m}$ & Vertical radius of & $26 \mathrm{~m}$ \\
& & gyration, $K_{Z Z}$ & \\
& & &
\end{tabular}




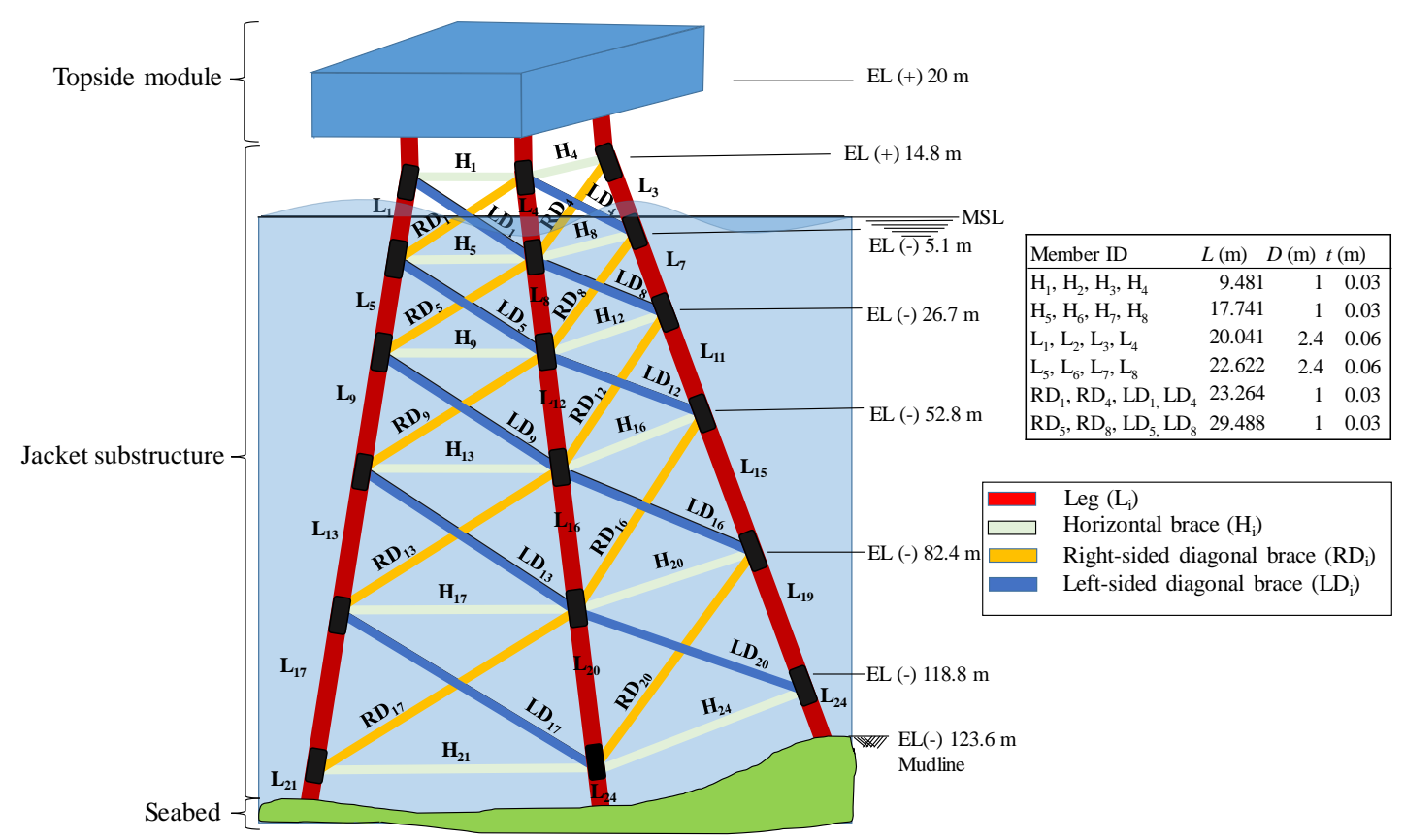

Fig. 5. Schematic diagram of jacket platform showing the sequential numbering of tubular members and their scantling properties.

In this paper, a typical bulbous bow model provided in DNV GL [20] was used. Figure 6 (a) shows the various internal components and the configuration of bow structure, and Table 2 lists some key scantling features. The stem/forecastle of the bow protrudes outwardly more than the bulb portion, and therefore, for the ease of locating initial contact and damage, the bow structure was divided into the bulb and stem portions, as shown in Fig. 6 (b).

Table 2. Scantling details of the OSV bow model.

\begin{tabular}{ll}
\hline Particulars & Dimension \\
\hline Bow height & $14.9 \mathrm{~mm}$ \\
Bulb height & $9.1 \mathrm{~m}$ \\
Stem height & $5.8 \mathrm{~m}$ \\
Bow breadth & $17.04 \mathrm{~m}$ \\
Forecastle hull plate thickness & $12 \mathrm{~mm}$ \\
$\begin{array}{l}\text { Bulb hull plate thickness } \\
\text { Transverse frame thickness }\end{array}$ & $11 \mathrm{~mm}$ \\
$\begin{array}{l}\text { Distance between transverse frames (in } \\
\text { the bulb) }\end{array}$ & $10 \mathrm{~mm}$ \\
$\begin{array}{l}\text { Distance between transverse frames (in } \\
\text { the forecastle) }\end{array}$ & $1.8 \mathrm{~mm}$ \\
$\begin{array}{l}\text { Protrude of forecastle from the bulb } \\
\text { (along bow direction) }\end{array}$ & $35 \mathrm{~mm}$ \\
\hline
\end{tabular}




\begin{tabular}{ll}
\hline $\begin{array}{l}\text { Protrude of forecastle from the bulb } \\
\text { (along port/starboard direction) }\end{array}$ & $6.5 \mathrm{~m}$ \\
$\begin{array}{l}\text { Bulb radius (along centerline) } \\
\text { First deck plate thickness }\end{array}$ & $2 \mathrm{~m}$ \\
Second deck plate thickness & $7.5 \mathrm{~mm}$ \\
Third deck plate thickness & $7 \mathrm{~mm}$ \\
Bulbous deck plate thickness & $9 \mathrm{~mm}$ \\
Transverse frame plate thickness & $12 \mathrm{~mm}$ \\
$\begin{array}{l}\text { Transverse stiffener plate thickness } \\
\text { (bulb and forecastle) }\end{array}$ & $7 \mathrm{~mm}$ \\
\hline
\end{tabular}

(a)

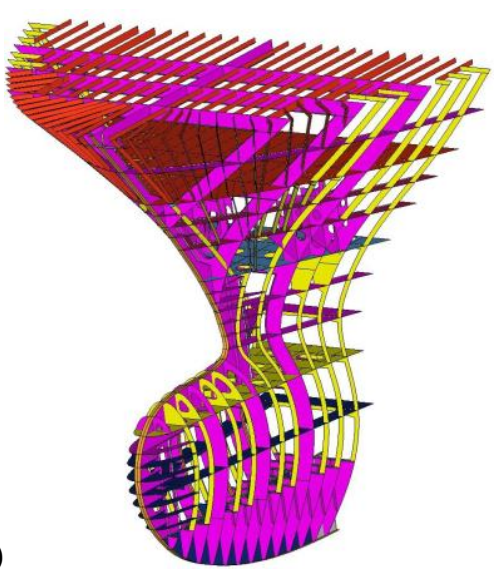

(b)

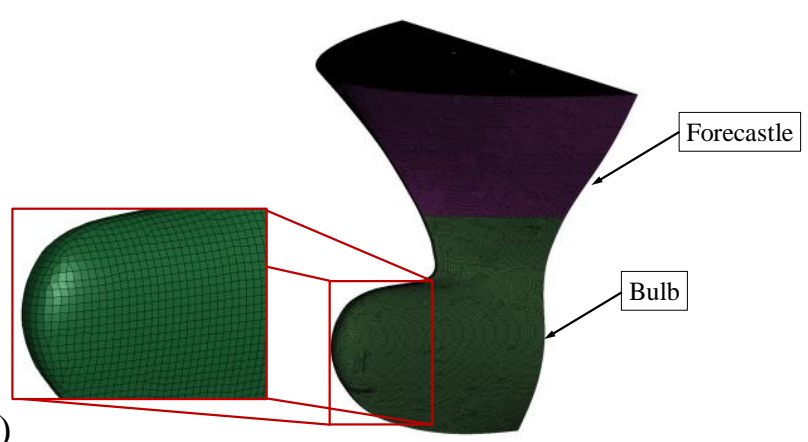

Fig. 6. The OSV's bulbous bow model used in the study [obtained from DNV GL [20]: (a) internal components and configuration, (b) meshed model showing the forecastle and bulb sections.

\subsection{The extent of structures for numerical analysis}

A full-scale jacket substructure part consisting of columns and braces is considered in the study to account for the load distributions among different members, as shown in Fig. 4. The soil foundation was not modelled here, as the collision between supply vessel and platform is governed by minor collisions, which are defined as collision events characterised by low-impact velocities, incurring reparable damages to the platform and which does not call for cease of operation [21]. Therefore, the effect of soil characteristics on the damage of the platform is negligible [15,22]. Also, it is assumed that there is enough clearance between platform freeboard and sea level so that there exists no chance of any part of the vessel colliding to the topside module.

For the purpose of an illustrative example, only collision scenarios between a supply vessel approaching to an offshore platform were considered in the present study. On the other hand, one can perform stern and sideways collisions using the techniques developed here. As such, only the OSV's bow section was modelled with its total mass at full load condition which was applied at the centre of mass, allocated 
at a longitudinal distance of $41.5 \mathrm{~m}$ from the aft part of the ship. The dynamic motion of the ship was implemented, where the total mass of the OSV was uniformly distributed to the bow section through rigid bar elements, as shown in Fig. 7.

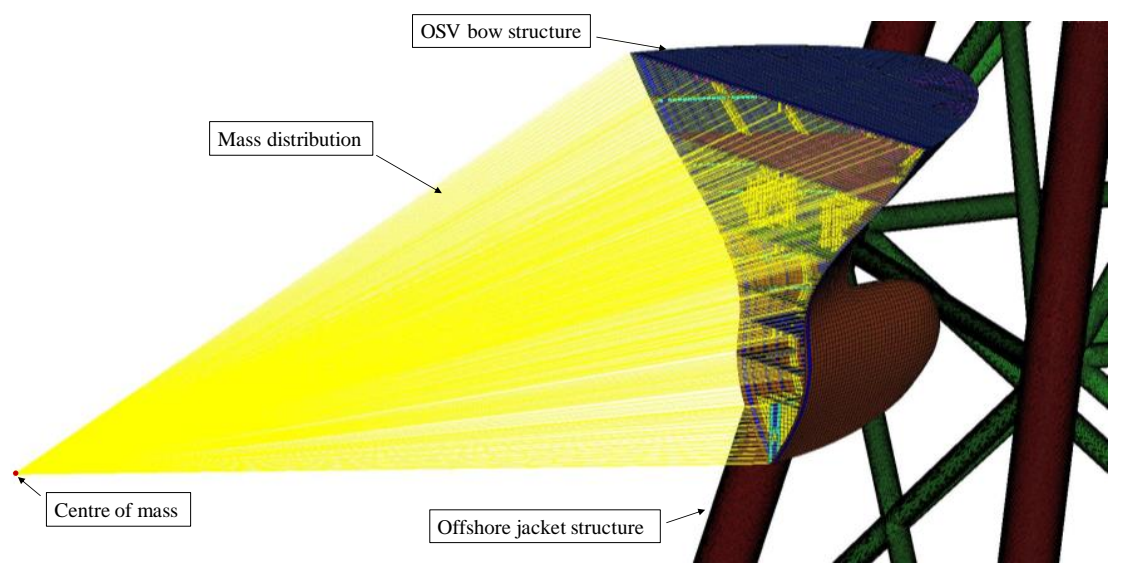

Fig. 7. An example showing an initial setup of a collision scenario for crashworthiness analysis; a group of straight lines shows the relative position and distribution of the centre of mass to the bow structure.

\subsection{Mesh modelling}

The target structures involved in a collision were numerically analysed using finite element models. The size of the finite element (mesh) should be chosen fine enough such that it should be able to capture different failure mechanisms such as crushing, fracture (tearing or cutting), and a large plastic straining with reasonable accuracy. For large structures such as ships and offshore platforms, as a general principle, at least fine mesh should be used in the collision zone to reduce the computational effort $[1,10]$.

Four-node Belytschko-Lin-Tsay plate-shell elements [23] based on Reissner-Mindlin kinematic assumption with five through-the-thickness integration points were used for analysing collision dynamics. The quad-type elements provide higher computational efficiency than the triangular elements.

Paik [1,6] proposed the following guideline to define the 'best' mesh (plate-shell plate element) size which is recommended to be smaller than $\mathrm{H} / 8$, as follows:

$$
s \leq \frac{H}{8}
$$

where $s$ is the mesh size and $H$ is the half-fold length of the plate element. Various formulations are available to predict $H$. For example, Wierzbicki and Abramowicz [24] developed an empirical formula to estimate $H$ as follows:

$$
H=0.983 b^{2 / 3} t^{1 / 3}
$$

On the other hand, Storheim and Amdahl [8] suggested that the chosen mesh size should be in the range of 5 to 10 times of plate thickness to capture dynamic strain 
and fracture with sufficient accuracy, and recommended practice suggests that the $s / t$ shall be approximately 5. Simplified analytical equations and recommendations are useful to define 'optimum mesh size' because costly convergence studies are not necessary $[1,6]$.
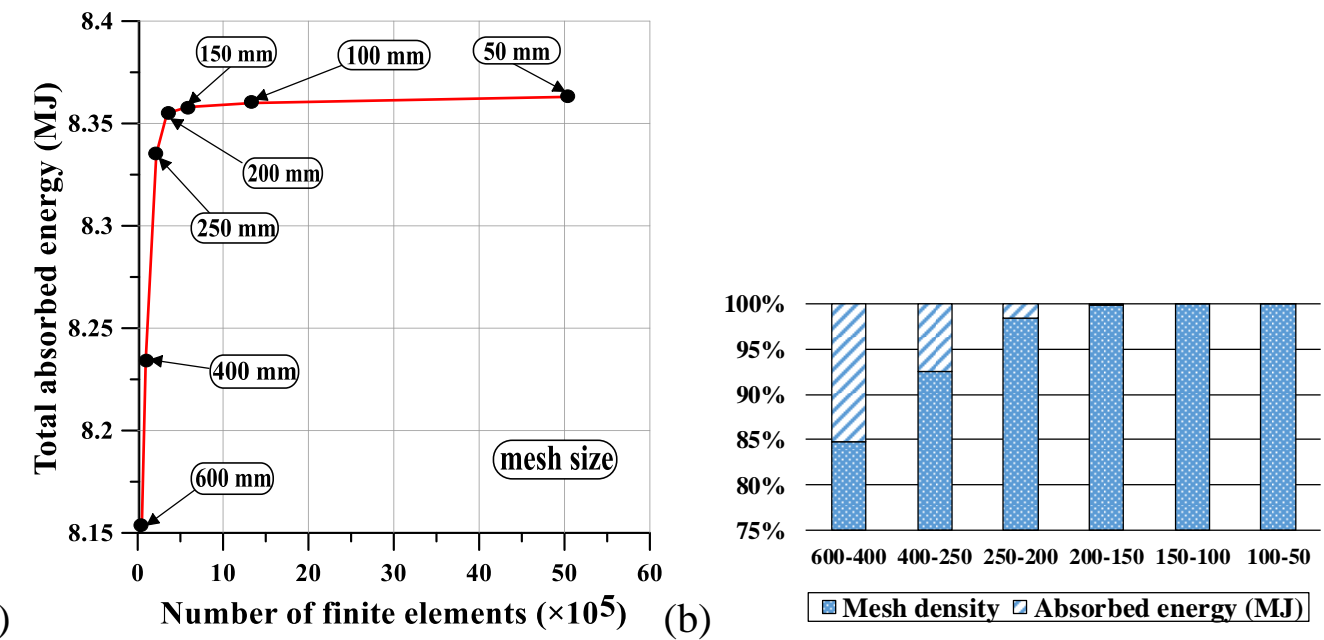

Fig. 8. Results of mesh convergence study for different mesh sizes: (a) energy absorbed by jacket vs the number of finite elements, (b) percentage difference of absorbed energy, and mesh density.

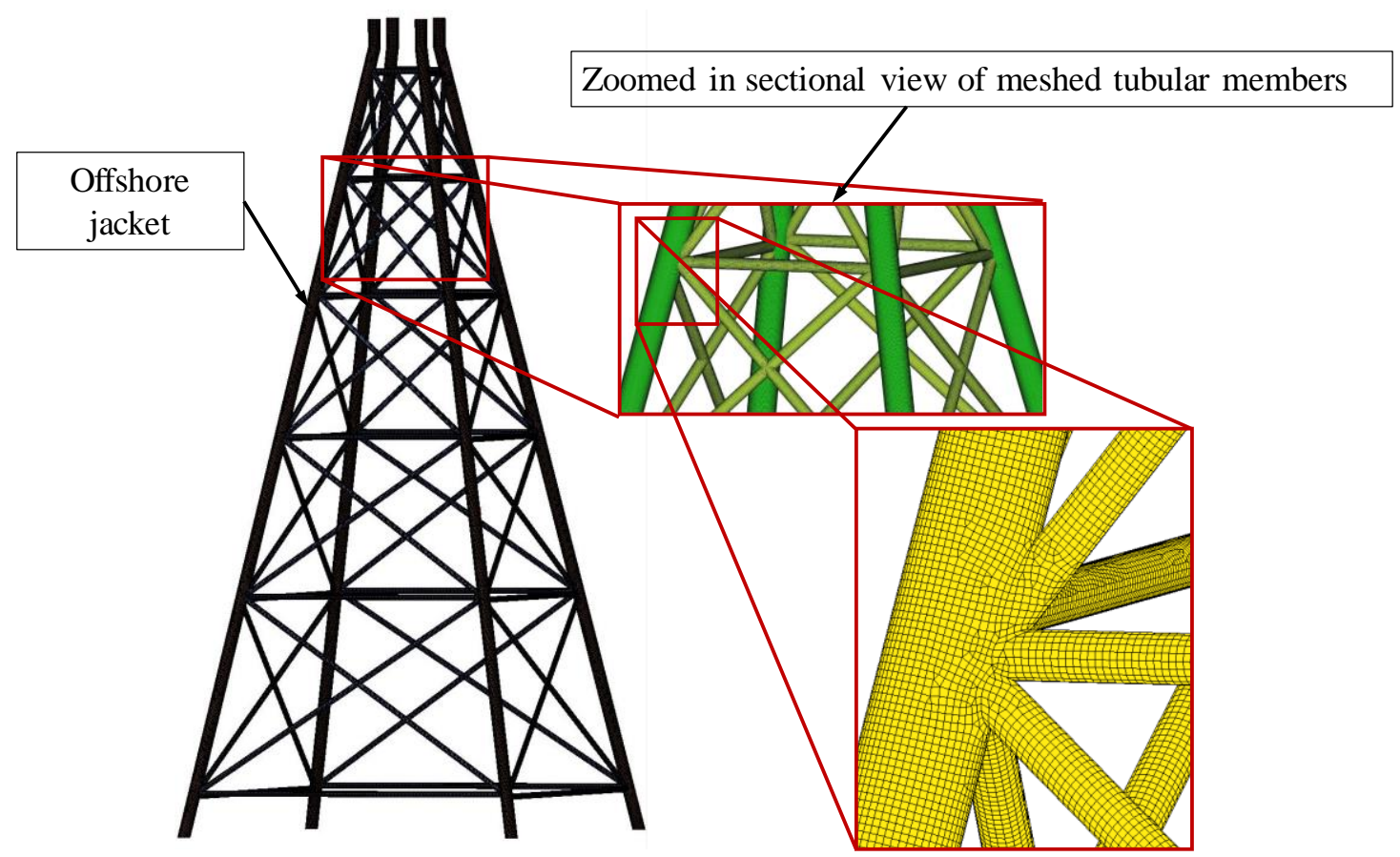

Fig. 9. Four-legged offshore jacket platform: substructure segment consisting of columns and braces (left), enlarged sectional view depicting meshed tubular members (right). 
In this study, however, a convergence study was conducted in terms of strain energy and deformation, as shown in Fig. 8. Figure 8 (a) demonstrates the results of a mesh convergence study for seven different element sizes, namely, 600, 400, 250, 200, 150,100 , and $50 \mathrm{~mm}$. It is worth noting that a further increase in mesh size after 200 mm causes no visible refinement in the absorbed energy, as shown in Fig. 8 (b). The mesh density corresponding to $50 \mathrm{~mm}$ mesh size is approximately five times larger as compared to $200 \mathrm{~mm}$, however, with little improvement in the solution (i.e., 0.0007 MJ). Therefore, refinement past $200 \mathrm{~mm}$ mesh size is an inefficient application of NLFEA, which was chosen to be the best mesh size of the target structures. Moreover, the selected mesh size is in good agreement with the criteria, $s / t$ of 5 to 10 , as suggested by Storheim and Amdahl [8]. Figure 9 shows the resultant meshed model of the jacket platform.

\subsection{Material modelling}

An accurate definition of material properties is essential to capture the different failure mechanisms in collision scenarios. Table 3 provides the mechanical properties of the steel used for modelling the target structures. DH36 high-tensile steel with a yield stress of $383.7 \mathrm{MPa}$ is used for the target structures, which complies with the minimum yield stress value of $350 \mathrm{MPa}$, specified by API [25] for offshore installations. The 'mat_024_piecewise linear plasticity' card is used to model constitutive material in LS-DYNA.

Table 3. Material properties of target structures [6]

\begin{tabular}{|c|c|}
\hline Features (unit) & Description \\
\hline Material & $\begin{array}{l}\text { High-tensile steel, } \\
\text { DH36 }\end{array}$ \\
\hline Density, $\rho\left(\mathrm{kg} / \mathrm{m}^{3}\right)$ & 7850 \\
\hline Modulus of elasticity, $E(\mathrm{GPa})$ & 205.8 \\
\hline Poisson's ratio, $v$ & 0.3 \\
\hline Yield stress, $\sigma_{Y}(\mathrm{MPa})$ & 380 \\
\hline \multirow{2}{*}{$\begin{array}{l}\text { Cowper-Symonds } \\
\text { coefficients }\end{array}$} & 3200 \\
\hline & 5 \\
\hline
\end{tabular}

\subsubsection{Use of true stress-true strain relationship}

For the ultimate limit state (ULS) design of offshore structures, strains are small enough until and after the ultimate strength is reached without necking of material. Therefore, the engineering stress-engineering strain relationship of material can be used, i.e., using elastic-perfectly plastic material model without the strain-hardening effect. On the other hand, the accidental limit state (ALS) design is associated with 
large strains of structures involving crushing and fracture where straining hardening and necking of material cannot be neglected [26].

In this case, the true stress-true strain relationship of material should be employed. Figure 10 shows a true stress-true strain relationship of high-tensile steel with grade $\mathrm{DH} 36$ at room temperature $\left(20^{\circ} \mathrm{C}\right)$ and a strain rate of 0.01 as obtained from MPDAS (Mechanical Property Database Management) software developed by Paik et al. [27], which utilises a multi-dimensional matrix option available in the MATLAB (matrix laboratory) programming language. MPDAS provides outputs such as stress-strain relations (engineering and true), yield stress, and ultimate tensile stress for various types of materials with different grades, temperatures, and strain rates.

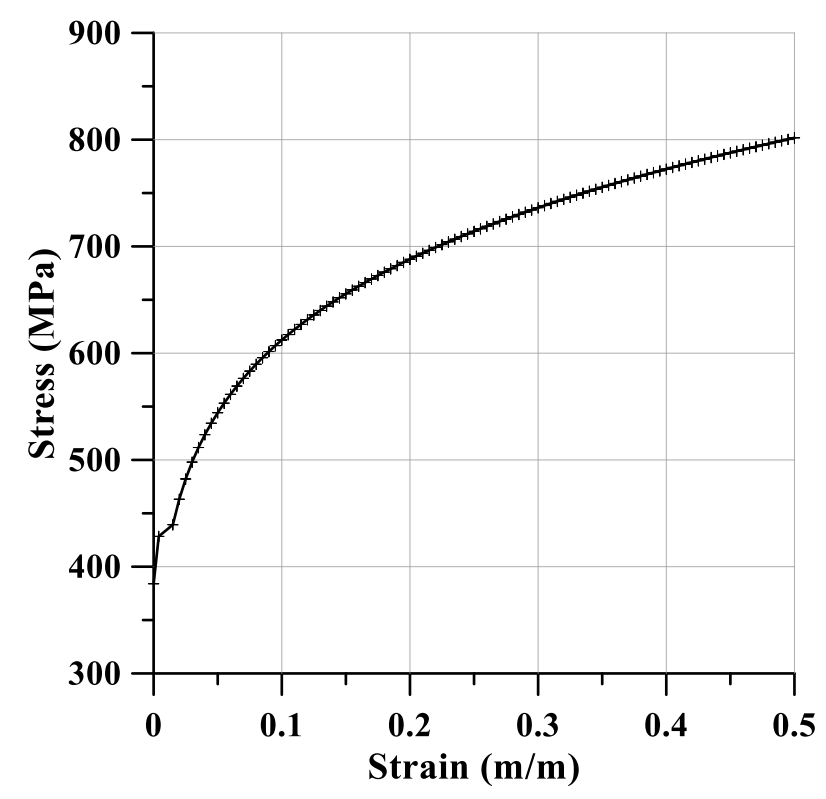

Fig. 10. A true stress-true strain diagram of high-tensile steel with grade DH36.

\subsubsection{Dynamic properties of the material}

The collision between a ship and an offshore structure is a dynamic phenomenon, and therefore, dynamic material properties should be defined carefully.

\subsubsection{Calculation of strain rate}

Strain rate $(\dot{\varepsilon})$ (or speed of impact loading) significantly affects the dynamic properties of the material $[28,29]$. It is considered to be the primary factor affecting collision mechanics and structural crashworthiness. It is defined as the ratio of the loading speed to structural displacement,

$$
\dot{\varepsilon}=d \varepsilon / d t
$$

where $\varepsilon$ is the plastic strain and $t$ is the time. It affects the plastic flow of some materials known as material strain rate sensitivity or viscoplasticity [30]. Strain rate affects the material tensile properties and membrane fractures, which may deteriorate the quality of the stress-strain curve. 
The experimental databases on the effects of strain rates are available in the literature [31]. It is recognised that strain rate varies with different locations of the colliding bodies, which changes at different instances of time. Paik [6] proposed an expression for calculating strain rate based on the assumption that the initial velocity $\left(V_{0}\right)$ reduces linearly to zero during the deformation $(\delta)$ :

$$
\dot{\varepsilon}=\frac{V_{0}}{2 \delta}
$$

Neglecting stress concentration factor, HSE [32] provided the following relation for estimating the maximum strain rate:

$$
\dot{\varepsilon}=\frac{12 V_{0} D}{L^{2}}
$$

where $D$ and $L$ refers to the diameter and length of the tubular member, respectively, and $V_{0}$ is the collision velocity.

Ko et al. [33] proposed an empirical relation for strain rate as a function of collision velocity for ship-ship collisions as:

$$
\dot{\varepsilon}=2.970 V_{0}-0.686 \text { for } V_{0} \geq 0.231 \mathrm{~m} / \mathrm{s}
$$

The strain rate is calculated based on the maximum value observed at the tip of the vessel coming in contact with the platform. On calculating strain variation on the element, the strain rate is calculated by taking the time-derivative of the strain as follows:

$$
\dot{\varepsilon}_{m}=(d \varepsilon / d t)_{\text {initial_contact }}
$$

Figure 11 shows the time history of strain rate obtained for different initial collision velocities and dynamic fracture strains, where the maximum value is found in the initial stage of a collision period. Following the above pessimistic approach, the maximum strain rate measured at the initial contact position is used in the calculation of dynamic fracture strain. 


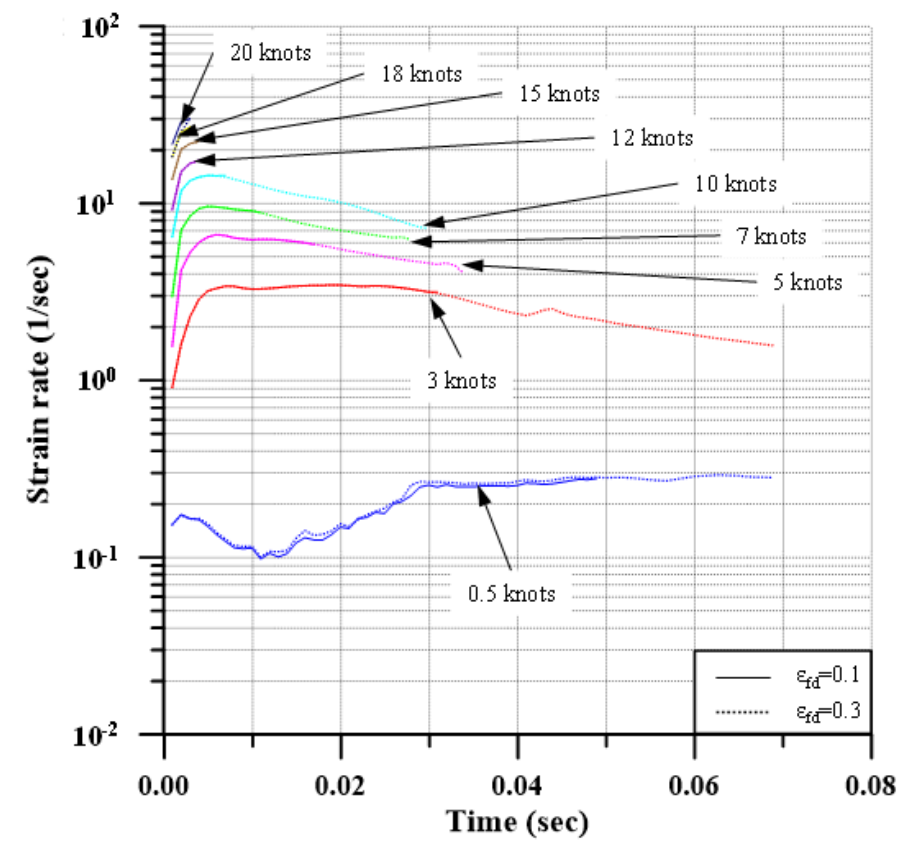

Fig. 11. Variation of strain rate in collision duration for different collision velocities and dynamic fracture strain [33].

\subsubsection{Dynamic yield strength}

Figure 12 shows the effect of strain rate on the dynamic yield stress of different materials based on the results obtained from various test studies conducted at different temperatures. It is observed that the dynamic yield stress increases exponentially with strain rate, and as the strain rate becomes greater, mild steel is more susceptible compared to high-tensile steel.

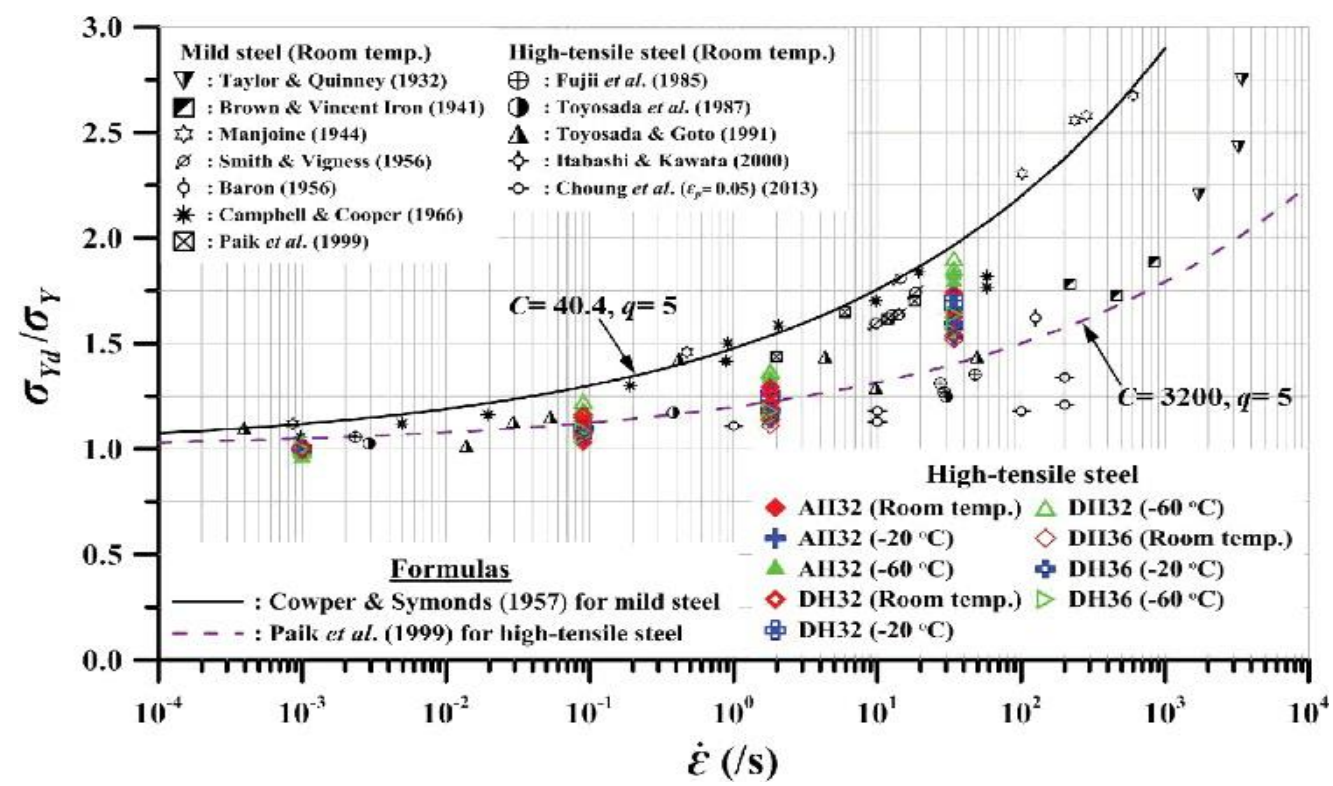

Fig. 12. Variation of dynamic yield strength with strain rate $[1,6,27]$. 
The Cowper-Symonds equation (C-S) [34] is commonly used to account for the strain rate sensitivity effect on the yield strength of the material in the form of dynamic yield strength $\left(\sigma_{Y d}\right)$,

$$
\sigma_{Y d}=\left[1+\left(\frac{\dot{\varepsilon}}{C}\right)^{\frac{1}{q}}\right] \sigma_{Y}
$$

where $\sigma_{Y}$ is the static yield strength, $C$ and $q$ are the C-S coefficients. The above expression is already built-in NLFEA packages such as LS-DYNA. On feeding the C-S coefficients $(C, q)$, LS-DYNA automatically calculates $\sigma_{Y d}$, with the strain rate calculated at each time step.

\subsubsection{Dynamic fracture strain}

Dynamic fracture strain defines the initiation of fracture in terms of plastic strain and affects the relative strength of the ship and jacket structures. It depends on the material strain rate, element size, and geometry of the structure [28].

Various analytical models to estimate fracture criteria for ship collisions and groundings have been developed, for example, RTCL (Rice-Tracey and Cockcroft-Latham) [35], BWH (Bressan-Williams-Hill) [36], Barba's law [37], among others [38-40]. Figure 13 shows the effect of strain rate on dynamic fracture strain obtained from Paik [6]. For a minor collision that involves low impact velocity, the effect of strain rate for high-tensile steel is less significant than mild steel. HSE [32] recommends a maximum fracture strain criterion of $15 \%$ in the parent material and $10 \%$ in the weld material for numerical analysis. DNV [41] recommends a critical fracture strain value of $15 \%$ for S355 high tensile steel. Paik [42] provides the following strain-based fracture criteria for simulation of ship collisions:

$$
\varepsilon_{e q} \geq \varepsilon_{f c}
$$

where $\varepsilon_{e q}$ and $\varepsilon_{f c}$ are the equivalent maximum tensile strain and critical fracture strain, respectively. The critical fracture strain $\left(\varepsilon_{f c}\right)$ depends on the material model (stress-strain relations), mesh size, structural geometry, and strain rate. 


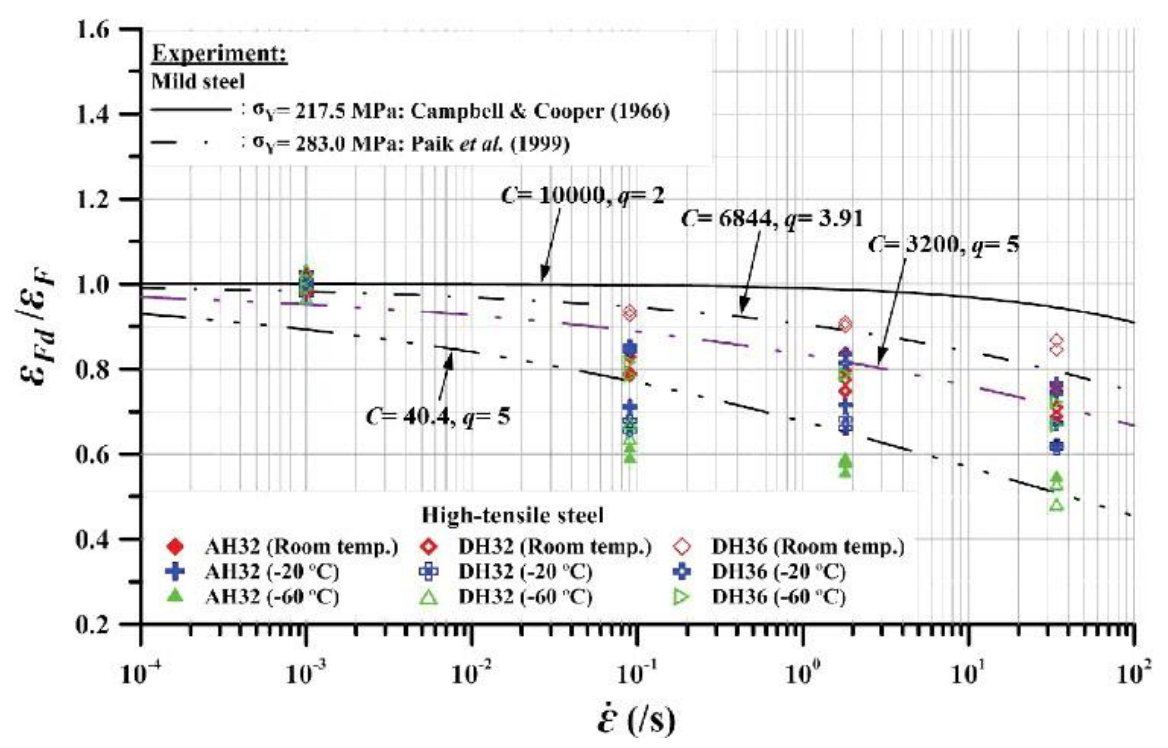

Fig. 13. Variation of dynamic fracture strain with an increasing strain rate $[1,6,27]$.

Unlike dynamic yield strength, the fracture strain $\left(\varepsilon_{f d}\right)$ should be manually entered to LS-DYNA, which is calculated using the inverse C-S equation given by Jones [43] as follows:

$$
\varepsilon_{f d}=\xi\left[1+\left(\frac{\dot{\varepsilon}}{C}\right)^{\frac{1}{q}}\right]^{-1} \varepsilon_{f c}
$$

where $\varepsilon_{f_{c}}$ is the critical fracture strain and $\xi$ is the ratio of the static and dynamic energies absorbed in a material at rupture. If the energy to failure is assumed to be invariant, i.e., independent of $\dot{\varepsilon}$, then it may be taken as $\xi=1$ so that the energy absorbed in the dynamic case is equal to that absorbed in the corresponding static case.

Hughes and Paik $[1,6,44]$ provided an expression for calculating $\varepsilon_{f c}$ based on element thickness and mesh size as

$$
\varepsilon_{f c}=\gamma_{1} \gamma_{2} \varepsilon_{f}
$$

in which $\varepsilon_{f}$ is the static fracture strain, obtained from the tensile coupon test. Paik et al. [27] provided a database of test results for various types of steel and aluminium and suggested $\varepsilon_{f}=0.32$ for high-tensile steel, which is used for our computations. $\gamma_{1}$ is a factor associated with mesh size $(s)$ and material thickness $(t)$ given by, 


$$
\gamma_{1}=d_{1}\left(\frac{t}{s}\right)^{d_{2}}
$$

where $d_{1}$ and $d_{2}$ are coefficients calculated based on the tensile coupon test. Paik and Thayamballi $[1,6,45]$ suggested $d_{1}=4.1$ and $d_{2}=0.58$ for mild steel having a thickness of $2 \mathrm{~mm} . \gamma_{2}$ is knock-down or correction factor which accounts for local bending due to folding $(0.3-0.4)$. A conservative value of 0.3 is used in our computations.

Using Eq. (9), as an example, Table 4 provides the calculated dynamic fracture strain values for the OSV bow, column, and brace of the jacket structures, for a collision scenario with a collision velocity of $1.65 \mathrm{~m} / \mathrm{s}$. Following the method described in section 4.2.1, the maximum strain rate is found to be $3.95 \mathrm{~s}^{-1}$, which is close to $4.2145 \mathrm{~s}^{-1}$ calculated using Eq. (8) for the ship-ship collision.

Table 4. Calculated dynamic properties of the material.

\begin{tabular}{llllll}
\hline $\begin{array}{l}\text { Structural } \\
\text { member }\end{array}$ & $\begin{array}{l}\text { Strain } \\
\text { rate, } \dot{\varepsilon} \\
\left(s^{-1}\right)\end{array}$ & $\begin{array}{l}\text { Finite } \\
\text { element } \\
\text { size, } s \\
(\mathrm{~mm})\end{array}$ & $\begin{array}{l}\text { Plate/tube } \\
\text { thickness, } t \\
(\mathrm{~mm})\end{array}$ & $\begin{array}{l}\text { Critical } \\
\text { fracture } \\
\text { strain, } \varepsilon_{f c}\end{array}$ & $\begin{array}{l}\text { Dynamic } \\
\text { fracture }\end{array}$ \\
strain, $\varepsilon_{f d}$
\end{tabular}

Figure 14 shows the comparison of time history plots of absorbed energy for column and brace members using constant dynamic fracture strain values of 0.15 of all the members, suggested by DNV and HSE for high-tensile steel and the values indicated in Table 4. As expected, for both the column and brace members, the initiation of fracture occurs early in the case with low dynamic fracture strain (i.e., 0.1037). It can be noted that both curves follow the more or less the same path until the initiation of fracture. Once fracture occurs, however, there is a significant deviation in the absorbed energy, where the effect is pronounced for brace than the column members. 

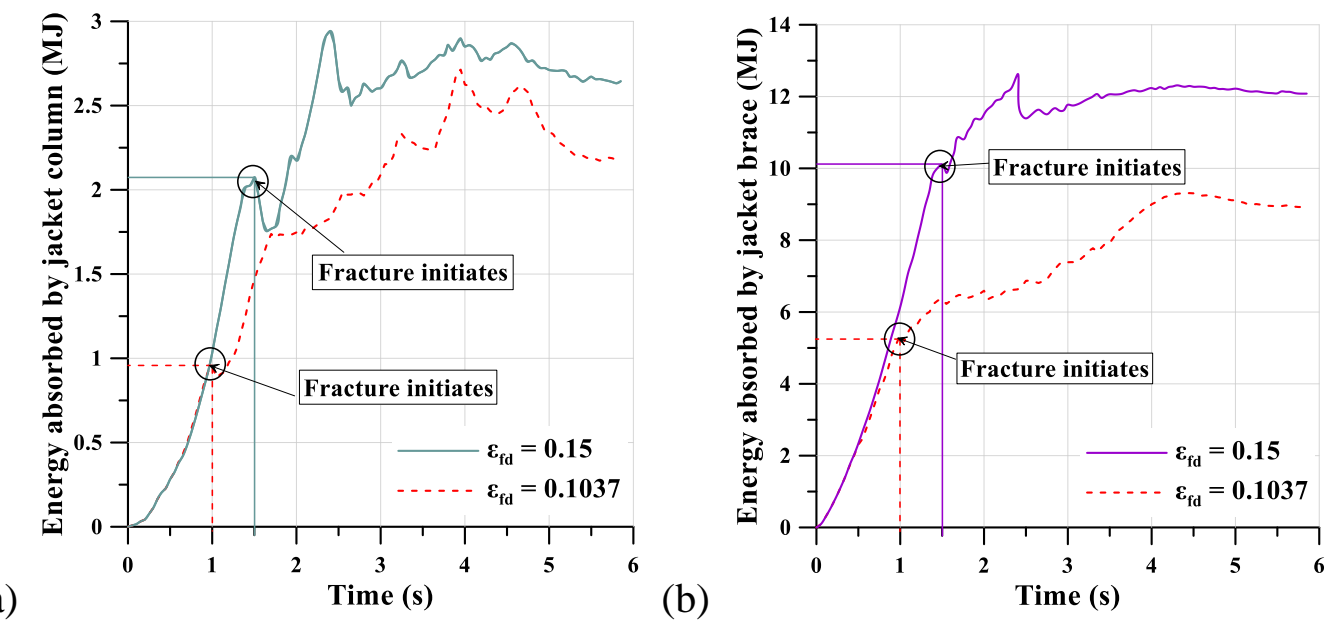

Fig. 14 Time history plot of absorbed energy for different dynamic fracture strain: (a) column and (b) brace

Figure 15 shows the importance of defining accurate fracture strain on the collision load to the platform. Four cases of fracture strain were considered- rigid, 0.15, no fracture, and fracture, as indicated in Table 4. It was observed that with no fracture defined, the curve tends to follow the rigid bow collision case. With a fracture strain of 0.15 , the peak load is reduced, the slope of the load curve is reduced, and the impact duration is increased, due to the occurrence of multiple fractures in bow and jacket members. The same effect is more pronounced for the scenarios with lower fracture strain values used in the study, where significant fluctuations in peak load can be observed due to fracture.

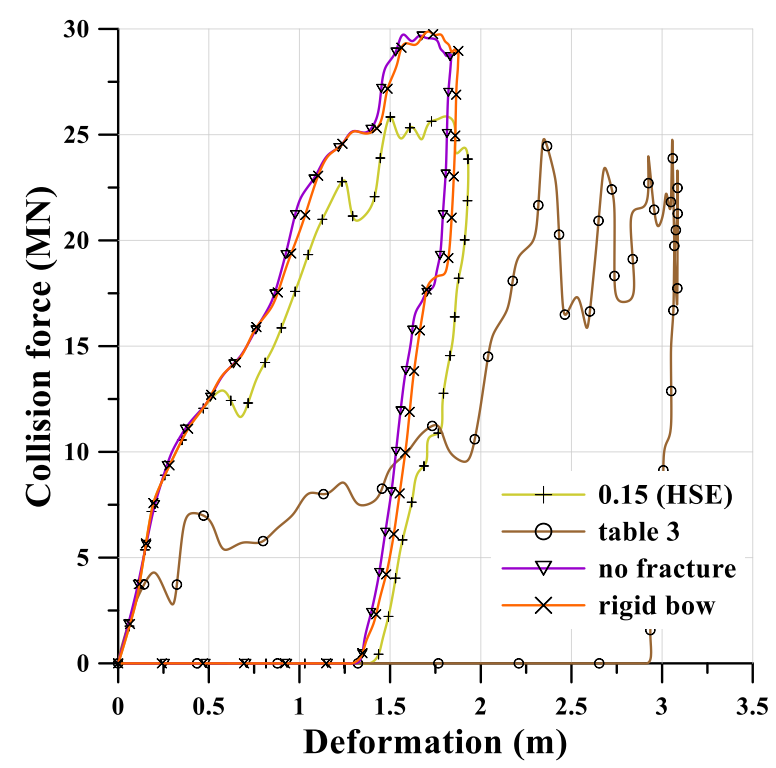

Fig. 15 Effect of different dynamic fracture strain values on the force-deformation diagram. 


\subsection{Surrounding water modelling}

Highly refined modelling of collision events in the vicinity of the contact area requires to capture not only the structural deformation but also the effect of the surrounding water to changing contact area and the desired failure modes. A dynamic simulation will trace the motion of the ship from its initial contact position through to its termination velocity. During a collision, apart from structural forces and moments, the hydrodynamic forces and moments act simultaneously due to the presence of surrounding water. The hydrodynamic term includes mass (including added mass), radiation, restoring (or buoyancy), and wave external force, which affects the ship motions during a collision.

Various analytical and numerical methods are available in the literature [28,46,47] to couple external ship dynamics and internal mechanics. This study uses the MCOL program of LS-DYNA $[48,49]$ to couple the interaction of ship motions and velocity between structural and hydrodynamic forces. MCOL has been successfully used for ship-ship collisions, for instance, [33,50-53]. Initially, MCOL was applied to ship-submarine collision [54,55]. Figure 16 shows a schematic representation of the numerical analysis of a collision between a ship and a submarine collision explaining the principle of coupling between MCOL and LS-DYNA.

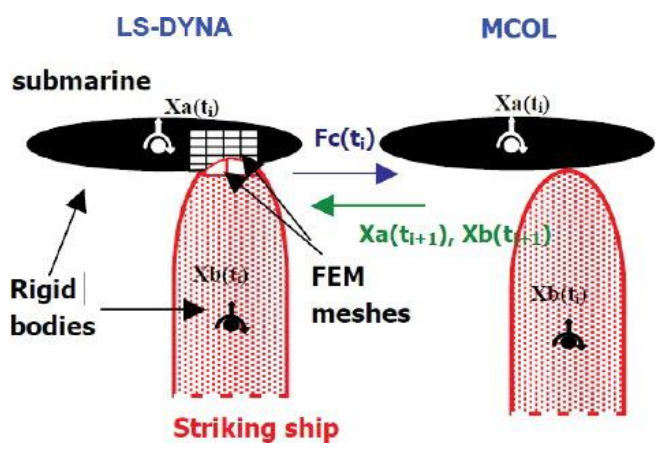

Fig. 16 Schematic diagram showing the working principle of coupling between MCOL and LS-DYNA [48].

MCOL uses convolution integral method to simulate the rigid body motion of the ships, which couples the force and moments due to structural impact and surrounding water at each time step. Mathematically, the equation of ship motion in a body-fixed reference frame $(x, y)$ is given by,

$$
M \dot{y}+G(y) \ddot{y}=\left[F_{w}+F_{H}+F_{V}\right](y, x)+F_{C}
$$

where the contact force, $\mathbf{F}_{\mathbf{C}}$ is calculated from structural analysis; $\mathbf{F}_{\mathbf{W}}, \mathbf{F}_{\mathbf{H}}$, and $\mathbf{F}_{\mathbf{V}}$ are the hydrodynamic wave forces, restoring forces and viscous forces, respectively; $\mathbf{M}$ and $\mathbf{G}$ represent total mass (including added mass) and gyroscopic matrices, respectively. More details on the theoretical background can be found in Ferry et al. [48].

The infinite frequency constant added mass along with the wave damping coefficient obtained for different wave pulsation are inputted to the MCOL. Following 
Pedersen and Zhang [56], the added mass coefficient for surge, sway, and yaw motions are taken as $0.05,0.85$, and 0.21 , respectively. The effect of other environmental load parameters, such as tide, current, and wind, is not considered here, assuming that sea state is calm during a collision.

Figure 17 shows a comparison of force-deformation curves for collision scenarios with and without using MCOL. As expected, both the peak force and deformation are less for the collision scenario without using MCOL because of the high impact energy accounting for surge added mass considered in MCOL. Also, it can be noted that both curves follow more or less the same path, which implies that the motion of the ship during impact has little effect on the collision damage.

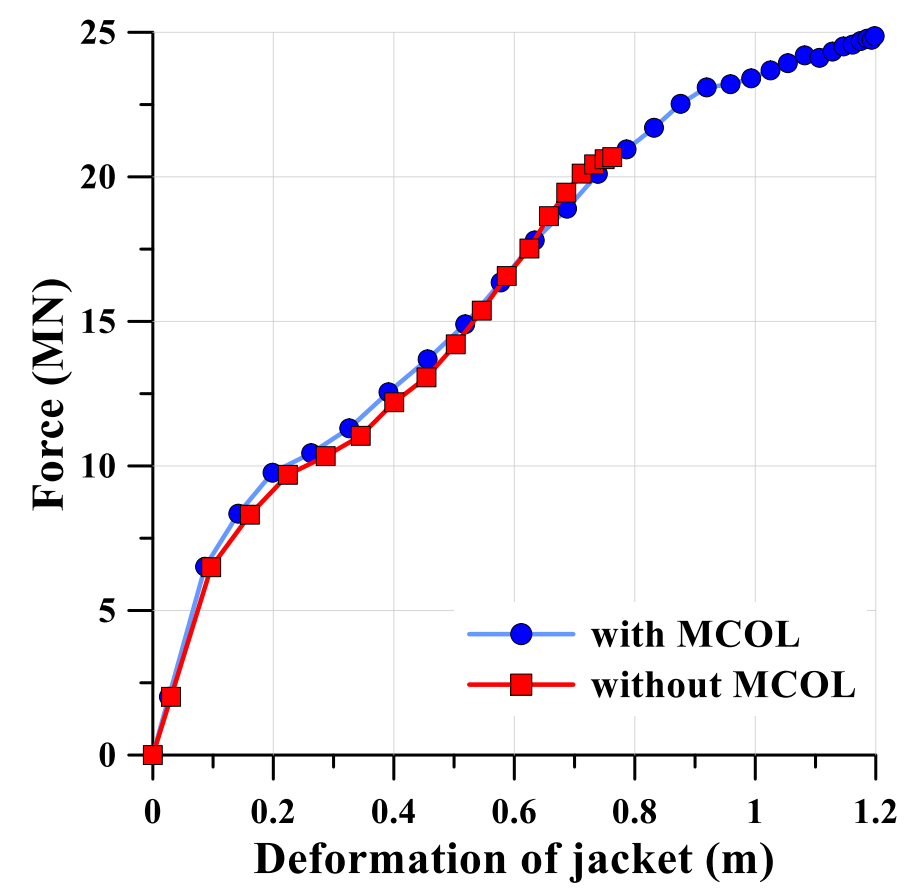

Fig. 17 Comparison of load-deformation diagram of jacket structure with and without using MCOL boundary condition.

\subsection{Surface contact modelling}

The accurate definition of the contact area is essential to capture the contact forces in a ship and platform collision. During a collision, a part of kinetic energy is dissipated in the form of contact friction. However, the accurate estimation of the frictional coefficient is challenging where grain elements on the contacting surfaces may vary among different mesh elements along with the presence of moisture due to seawater conditions, among other factors. Moreover, the frictional force invariably changes during a collision. In this context, the industry-accepted range for the frictional coefficient is $0.1-0.3$ [57]; a conservative value of 0.3 for the static and dynamic coefficient of friction is used in the present study.

Both the general (external) contact between the striking ship and the platform, and self (internal) contacts among different structural components of the ship (see Table 1) 
are analysed by invoking 'automatic_surface_to_surface' and 'automatic_single_surface' cards in LS-DYNA, respectively. A penalty-based contact algorithm was used to obtain collision loads. Figure 18 shows the comparison of force-deformation diagrams for external and internal contacts, derived from a typical collision scenario. The fluctuation of forces in self-contact represents the summation of internal forces between different internal structural components of the bow structure, which includes fracture of several elements. The peak self-contact force is found to be $0.12 \mathrm{MN}$, which corresponds to only $1 \%$ of general contact. Though this value is found to be insignificant, however, such negligence may cause significant error in the load-deformation curves for minor collisions.

(a)

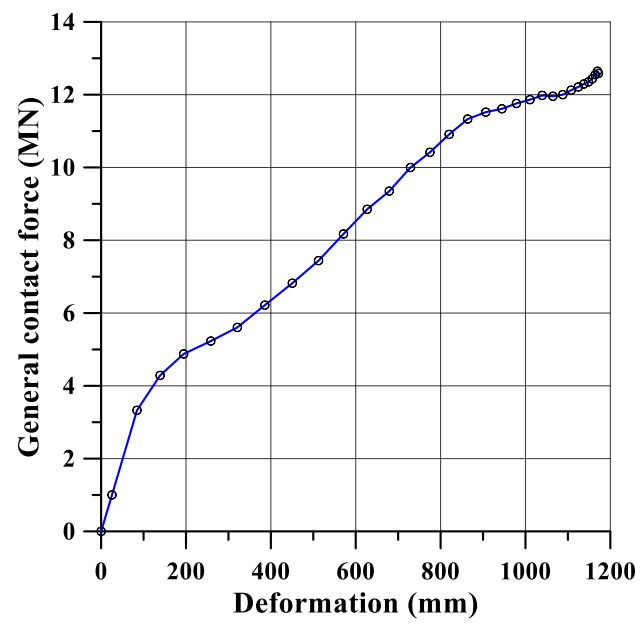

(b)

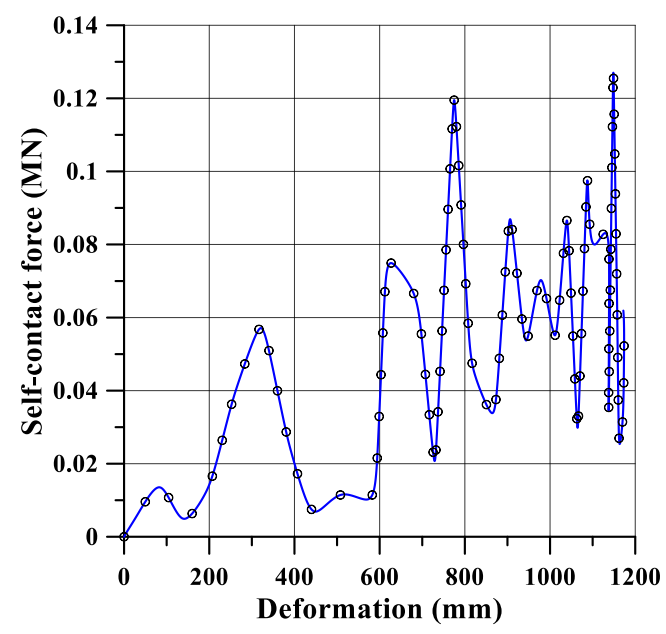

Fig. 18 Force-deformation diagram for contact modelling: (a) general contact and (b) self-contact.

\subsection{Damage failure modelling}

It is crucial to identify and model different failure mechanisms in association with the safety design and engineering of ship collisions. In general, the energy absorbed by the jacket platform is dissipated in the form of local denting and bending of tubular members as well as the global deformation of the platform. API [25] specifies that in the numerical analysis, denting and bending of the member is significant, while the global deformation of the platform can be conservatively neglected

The resulting dent shape and profile are governed by the collision parameters such as velocity, angle, and location, as well as the structural and material properties of the colliding bodies. Generally, the size of the bow structure is larger than the tubular members and covers the whole section of a tubular member.

Based on a series of test results conducted for different tube geometries, Zhu et al. [58] proposed a simple method to measure local and global deformations using the ratio of permanent deformation measured at upper and lower surfaces. The magnitude of this parameter enables us to precisely understand the deformation process and deformation modes along the axial direction. Figure 19 shows the schematic representation of a tubular member undergoing local denting and global bending 
under the action of the OSV bow impact. It is seen that the tube first deforms locally, followed by global bending. However, the transition of local to global or vice-versa depends on the relative strength and thickness of the colliding structures.

Different analytical expressions are available in the literature [14,59-62] for investigating this transition based on the indentation ratio and the relative resistance between denting and bending. Typically, local deformation is more pronounced for thin tubular members and the global deformation in thicker tubular members. With the introduction of more sophisticated nonlinear software, it becomes relatively easy to analyse resultant structural damages with high accuracy for different collision scenarios. To demonstrate the measurement of local denting and global bending of the tubular member followed in the study, Figure 20 shows the results of a sample collision scenario where a horizontal member undergoes deformation globally as well as locally under a collision velocity of $2 \mathrm{~m} / \mathrm{s}$. The global bending is measured to the neutral axis of the member, and the local denting is measured to the resultant deformation of the local elements.

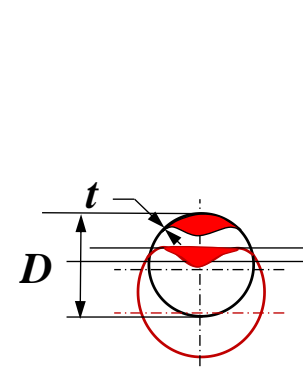

Side view

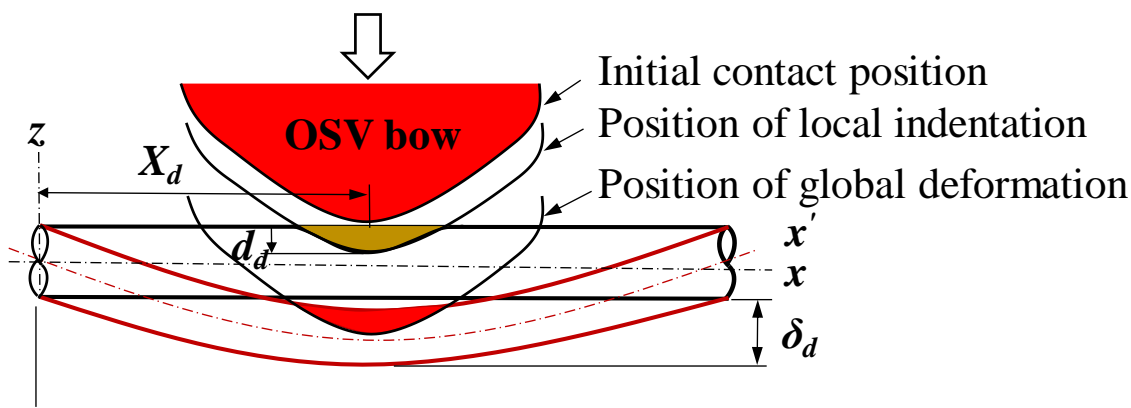

Front view

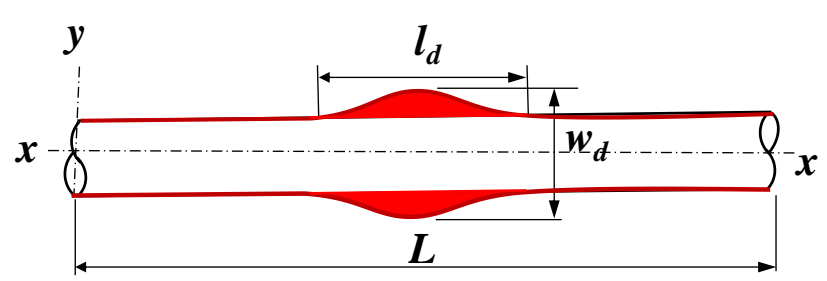

Plan view

Fig. 19 A schematic diagram showing local denting and overall bending characteristics of a tubular member under vessel bow impact: side, front, and top view. 


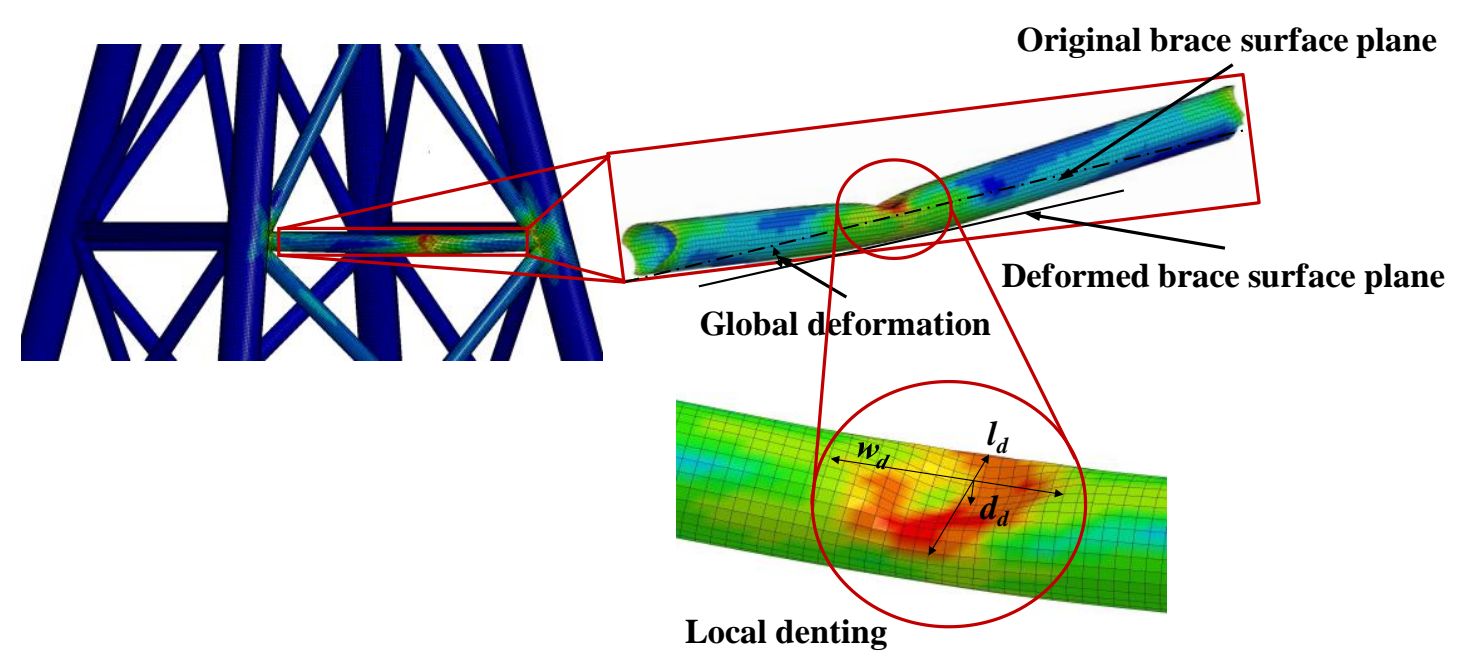

Fig. 20 An example of a collision scenario showing the measurement of global deformation and local dent characteristics.

\section{Analytical models of collision load analysis and their validation}

In the absence of experimental test studies on ship bow collision to jacket platform, the validation of the present study is performed with various analytical and empirical expressions available for the structural behaviour of tubes subjected to the lateral collision load of a striking body. For instance, Furnes and Amdahl [63] provided an analytical expression for the force $\left(F_{d}\right)$ required to locally dent $\left(\delta_{d}\right)$ the tubular members based on experimental test results:

$$
F_{d}=15 m_{p}(D / t)^{1 / 2}\left(2 \delta_{d} / D\right)^{1 / 2}
$$

where $m_{p}=\frac{1}{4} \sigma_{y} t^{2}$ is the plastic moment capacity of the tube wall; $D$ and $t$ are the diameter and wall thickness of the tube, respectively.

Considering the shape of the indenter, Ellinas and Walker [60] provided an empirical expression based on a series of test results:

$$
F_{d}=K m_{p}\left(\delta_{d} / D\right)^{1 / 2}
$$

where $K$ accounts for indenter shape, normally taken as 150 based on test results. The above two equations have been included in API [64].

DNV [65] provided an analytical equation for bow impact to tubular members, considering the contact surface between the structures as:

$$
F_{d}=\sigma_{y} \frac{t^{2}}{4} \sqrt{\frac{D}{t}}\left(22+1.2 \frac{B}{D}\right)\left(\frac{\delta_{d}}{D}\right)^{\frac{1.925}{3.5+\frac{B}{D}}}
$$


where $B$ is the height of the vertical plane section of the contact area. Based on a series of test results conducted by varying geometric and material properties of the tubes, Cho et al. [66] fitted an empirical equation to the test results as:

$$
\left.F_{d}=2 m_{p}\left(\frac{D}{t}\right)^{0.2}\left(\frac{E}{\sigma_{y}}\right)^{0.5}\left(\frac{\delta_{d}}{D}\right)^{0.45} e^{\left\{0.1\left(\frac{B}{D}\right)\left(\frac{\delta_{d}}{D}\right)^{-0.3}\right.}\right\}
$$

Wierzbicki and Suh [67] developed a theoretical equation considering the magnitude of the compressive or tensile force $(N)$, plastic yield stress in tension $\left(N_{p}\right)$ for different boundary conditions of the tube as:

$$
F_{d}=16 m_{p} \sqrt{\frac{\pi}{3}\left(\frac{D}{t}\right)\left(\frac{2 \delta_{d}}{D}\right)} \sqrt{\left\{1-\frac{1}{4}\left(1-\frac{N}{N_{p}}\right)^{3}\right\}}
$$

Figure 21 shows a comparison of load-deformation plots for different analytical equations and numerical results of a platform column subjected to a bow impact velocity of $1.65 \mathrm{~m} / \mathrm{s}$.

(a)

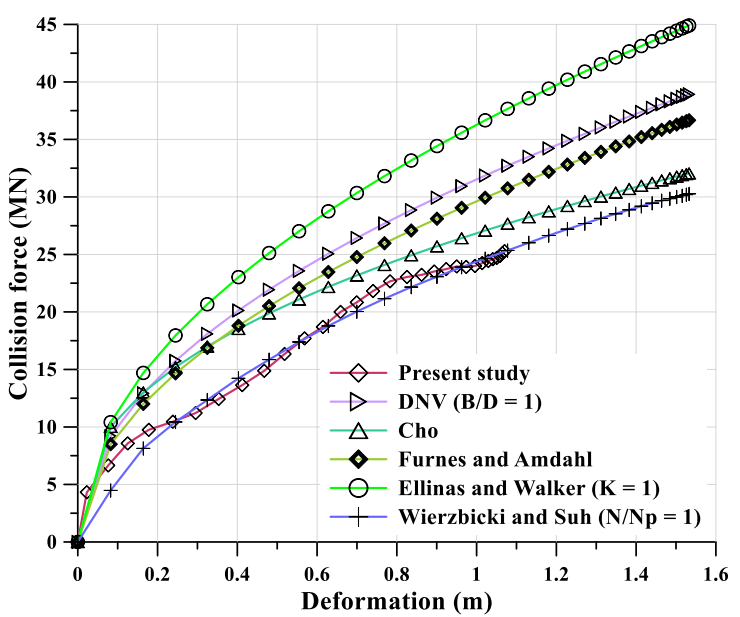

(b)

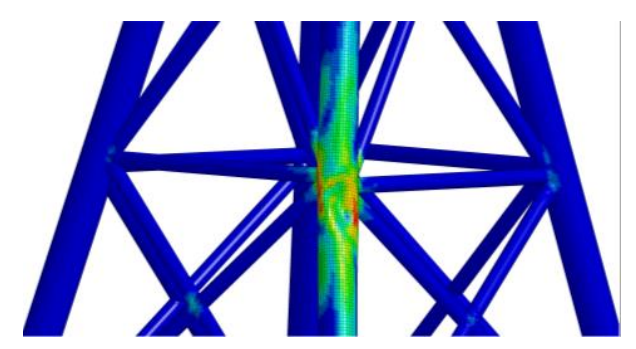

Fig. 21 (a) Comparison of force-deformation plots for different analytical and empirical equations with rigid bow collision to a jacket column member, (b) deformed column member of the jacket.

It can be seen that all the models show good agreement at low impact velocity; however, it tends to diverge with increasing velocity. This may be due to the effect of 
nonlinearities arising from geometric, material, and contact properties at higher impact velocities. This can be better understood by comparing NLFEM model used in the present study, where it follows a more or less similar path to the theoretical model of Wierzbicki and Suh [67] because it considers boundary condition explicitly and takes into account finite stiffness at jacket tubular members more effectively. On the other hand, the curve is uneven and conservative in terms of peak load and deformation because, in a real collision scenario, both ship and offshore structure absorb the impact energy (share-energy) and the absorbed energy in the jacket platform gets redistributed among the interconnected tubular member's by local denting and global deformation.

To study the effect of boundary conditions, Figure 22 shows a comparison of load-deformation graphs obtained based on three boundary conditions-fixed, freely sliding, and freely rotating, provided by Wierzbicki and Suh and rigid bow collision with a velocity of 2 and $3 \mathrm{~m} / \mathrm{s}$. It can be seen that the curves of the numerical study lie in between the sliding and rotating (which also includes freely sliding) because the jacket members are interconnected, having finite axial and rotational stiffness at the supports. Also, as the velocity of the rigid bow increases, the slope of the force curve increases and shifts upwards.

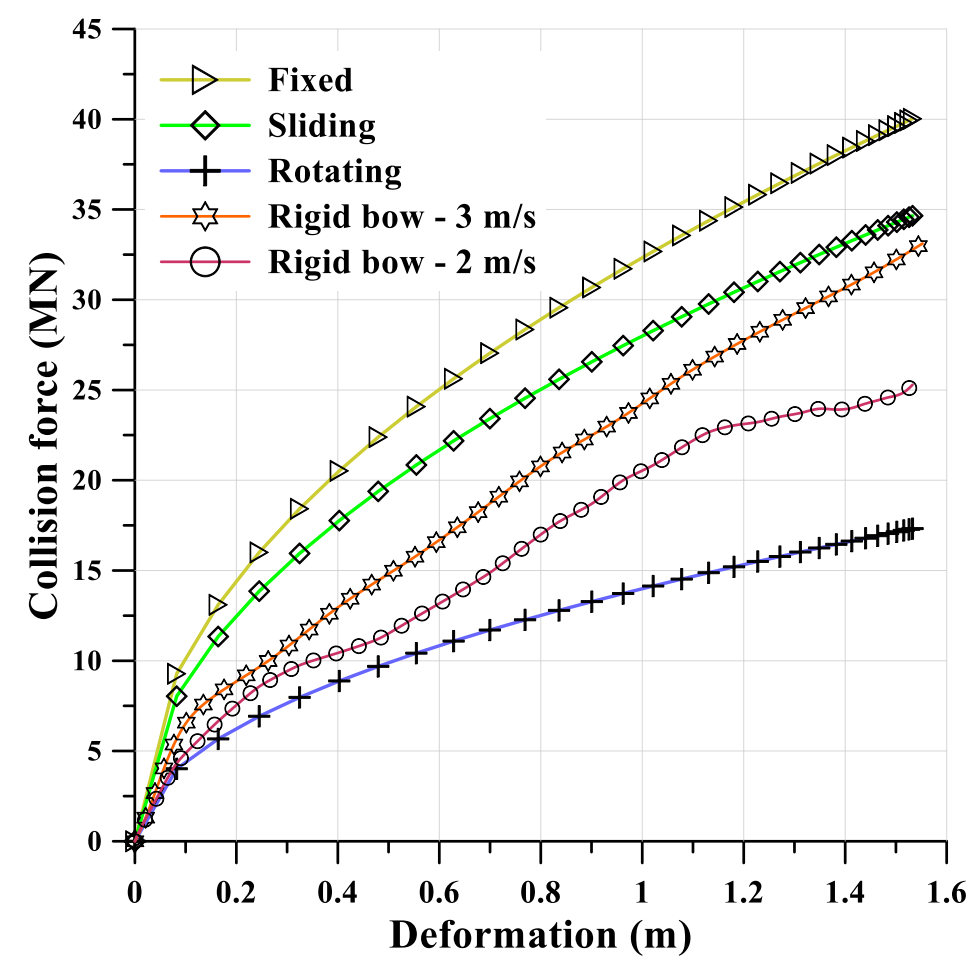

Fig. 22 Comparison of force-deformation graphs for the numerical and analytical study for different boundary conditions.

\section{Sensitivity study}

Using the modelling techniques described in section 3, a sensitivity study was conducted to investigate the effect of various collision affecting parameters on 
structural damage characteristics. This includes different collision velocities $-0.5,1,2$, 3 , and $4 \mathrm{~m} / \mathrm{s}$, column thickness - 40, 50, and $60 \mathrm{~mm}$, and impact location on the platform - column, brace, brace-brace joint, and brace-column joint.

Figure 23 shows an example of a force and an energy deformation curve obtained for the jacket and OSV bow structures. A separate load-deformation curve has been plotted for the brace and column, emphasising the importance of considering a full jacket model, as some portion of the total load gets distributed to the brace members as well. It can be seen that the amount of energy absorbed by the bow is less as compared to the column or brace members. Also, the energy absorbed by the column is higher than that of the adjoining brace members.
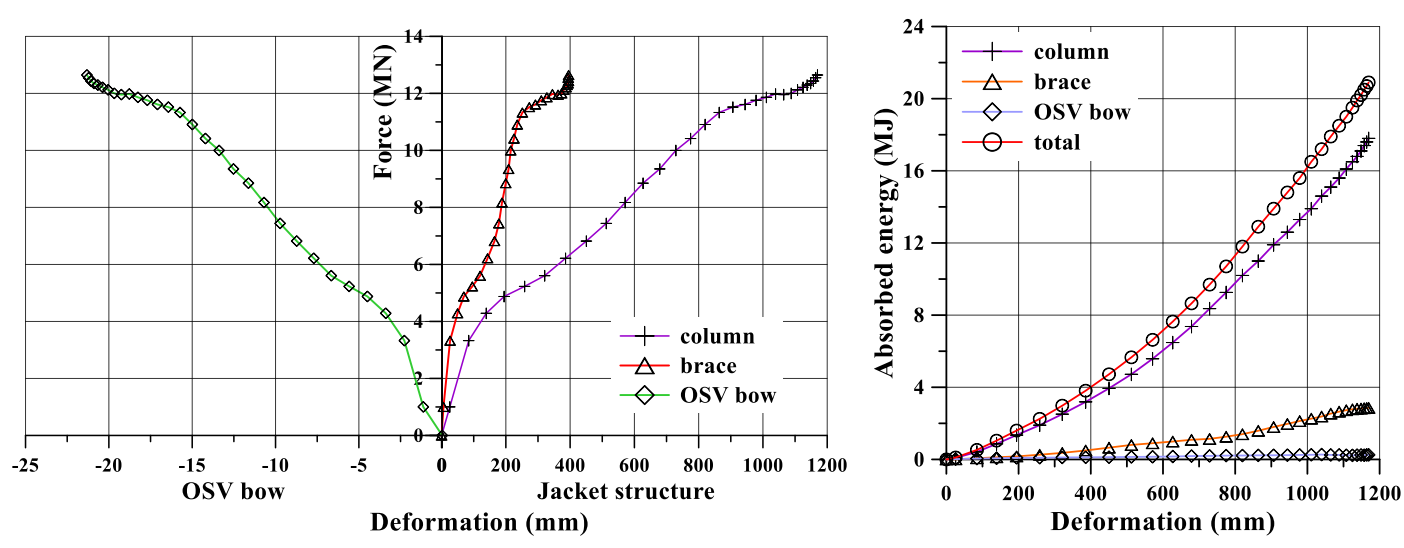

Fig. 23 Force- deformation (left) and energy - deformation (right) plots of a typical bow collision to jacket platform.

To investigate the effect of dynamic fracture strain on the relative strength between the interacting bodies, various simulations have been performed by changing the column thickness - 40, 50, and $60 \mathrm{~mm}$, keeping other load parameters such as velocity and impact location fixed. Table 5 summarises the calculated dynamic fracture strain values for different values of column thickness.

Table 5. Calculated dynamic fracture strains for various column thickness.

\begin{tabular}{ll}
\hline$t(\mathrm{~mm})$ & $\mathcal{E}_{f d}$ \\
\hline 40 & 0.1231 \\
50 & 0.1396 \\
60 & 0.1551 \\
\hline
\end{tabular}

Figure 24 (a) provides the energy absorbed by the platform and OSV bow structures obtained for varying column thickness and using a dynamic fracture strain of 0.15 for all structures and the 'original' values calculated in Table 5. It can be observed that the energy increases with decreasing column thickness. For all the scenarios, the energy absorbed is less for fracture strain 0.15 as compared to lower 
fracture values used in the study for a column while this observation is vice-versa for bow structure. Figure 24 (b) shows that the difference in total absorbed energy measured between the two fracture strains increases almost exponentially with an increase in the thickness. This implies that the dynamic fracture should be defined accurately and separately for different colliding members, especially for structures involving significant differences in relative strength.

(a)
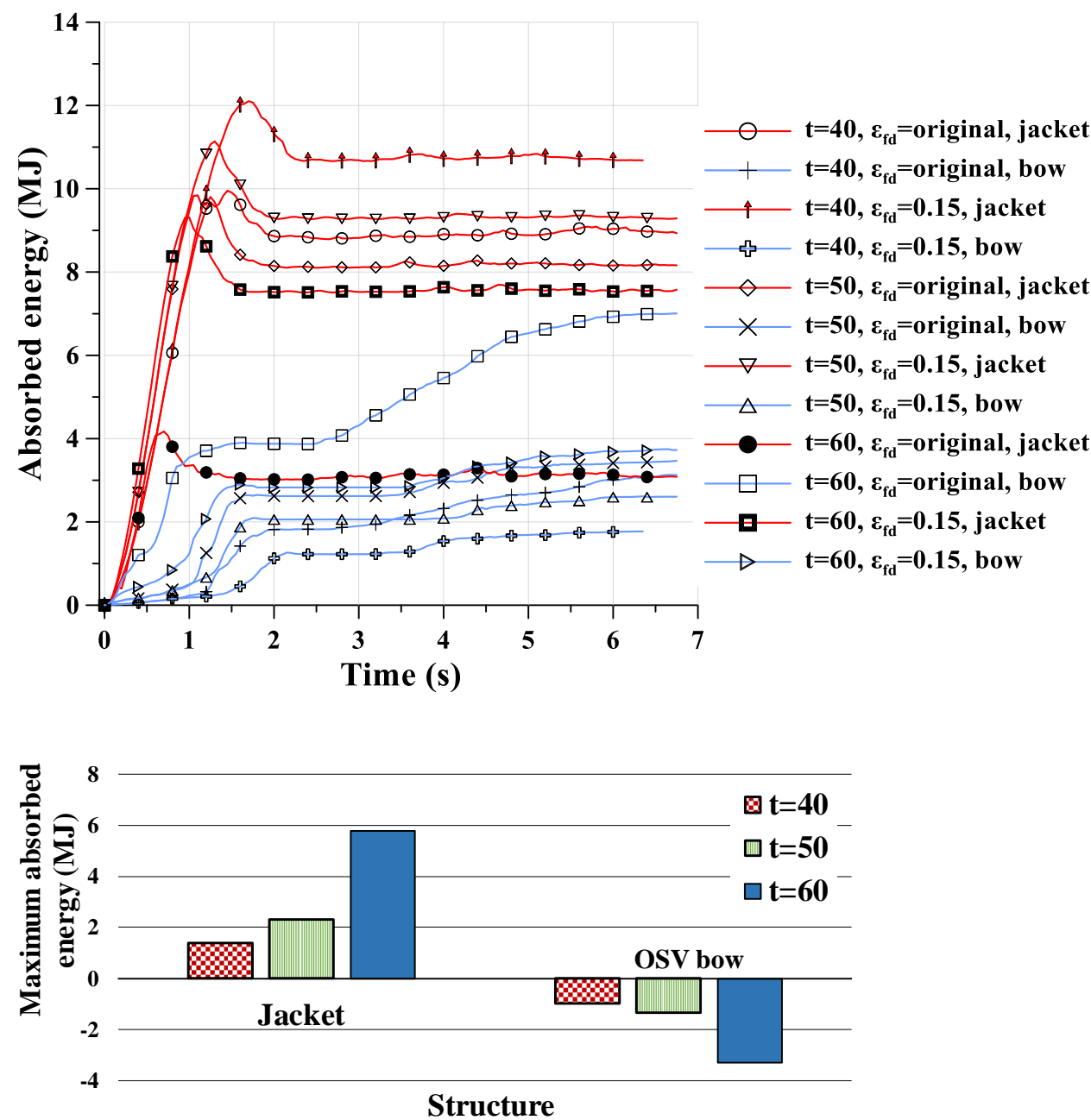

Fig. 24 Effect of dynamic fracture strain on the relative strength of OSV's bow and jacket structures: (a) time history of absorbed energy, (b) difference in maximum absorbed energy obtained for jacket and bow structures.

Among the different impact locations, the most critical case is found to be brace-brace joint impact scenarios due to its low load-carrying capacity. Figure 25(a) and (b) shows the strain contours of damage location for velocities $0.5 \mathrm{~m} / \mathrm{s}$ and $1 \mathrm{~m} / \mathrm{s}$. Initially, the bulb (i.e., the projected portion of the bow), contact at the brace joint, and as expected, only minor denting damage occurs with no occurrence of fracture. However, with further increase in velocity, i.e., $2 \mathrm{~m} / \mathrm{s}$, joint started to fracture, and at the same time, forecastle contacts with the horizontal brace $\left(\mathrm{H}_{8}\right)$, see, Fig 25(c). Finally, with more advance of the bow at higher velocities ( 3 and $4 \mathrm{~m} / \mathrm{s}$ ), forecastle 
damages adjoining diagonal braces $\left(\mathrm{LD}_{4}\right)$ and column $\left(\mathrm{L}_{3}\right)$ through local denting and global deformations, see Figs. 25(d) and (e). Figure 26 presents this collision process using force-displacement plots, where it can be observed that as the collision velocity increases, the peak contact forces between different parts occurs early.

(a)

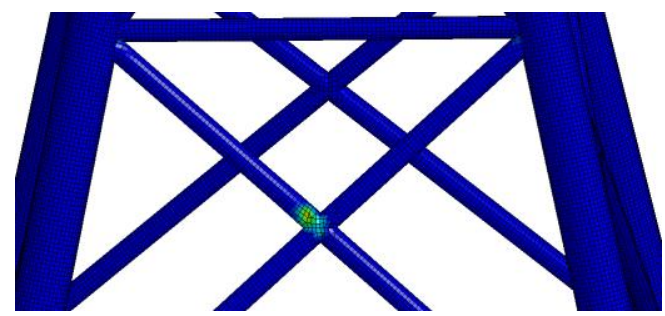

(b)

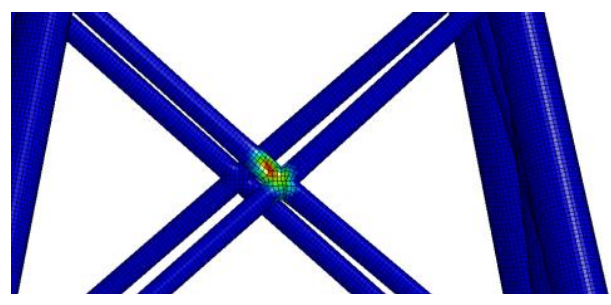

(d)

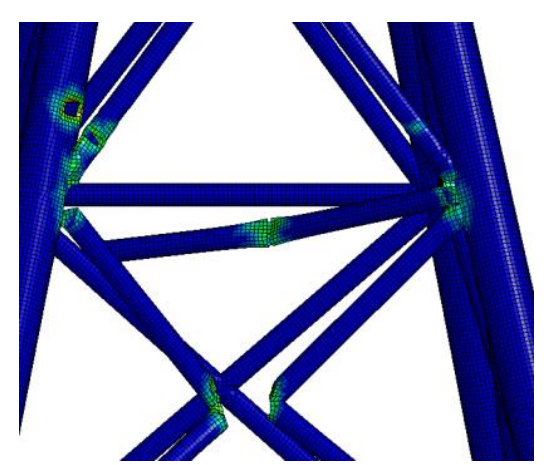

(c)

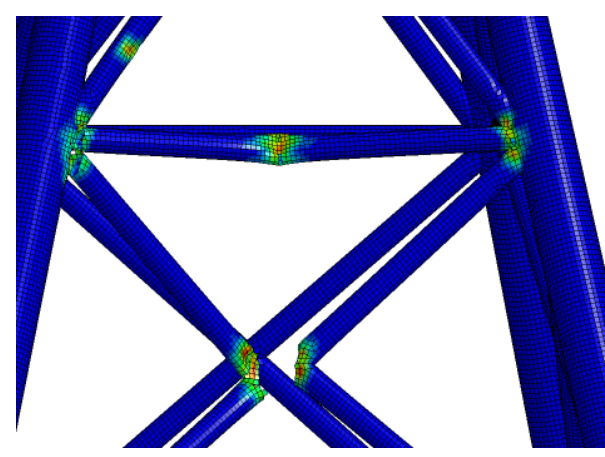

(e)

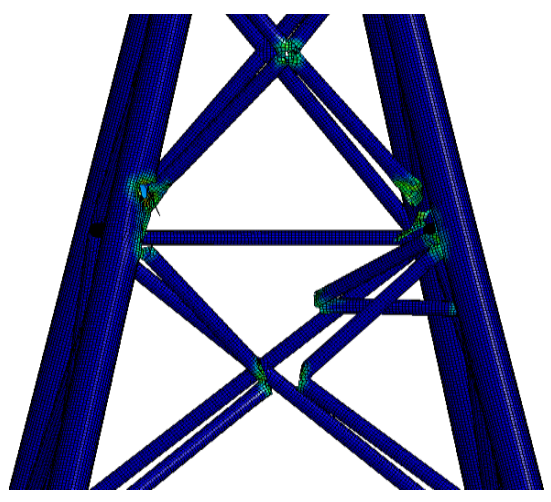

Fig. 25 Strain contour plots of the damaged platform due to bow impact for different collision velocities: (a) 0.5 , (b) 1 , (c) 2 , (d) 3 , and (e) $4 \mathrm{~m} / \mathrm{s}$. 


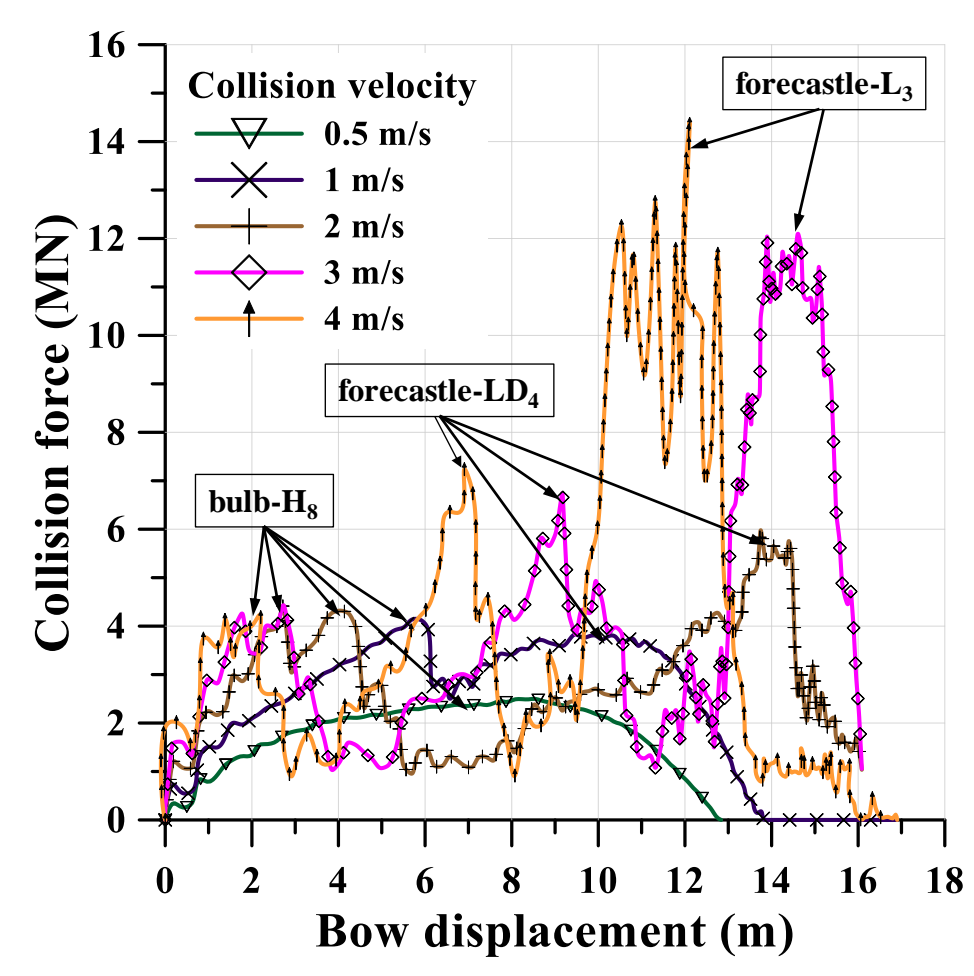

Fig. 26 Force-displacement plots for brace-brace joint collision scenarios for varying collision velocities.

Figure 27 shows the structural damage of the jacket platform and OSV bow, where bow hit a horizontal brace with a velocity of $4 \mathrm{~m} / \mathrm{s}$. Figure 28 presents the collision force and absorbed energy. It can be noticed that initially, there is only bulb contact with the horizontal brace member $\left(\mathrm{H}_{5}\right)$, but as the bow moves forward, the bulb contact force reduces. As the displacement reaches $2.75 \mathrm{~m}$, the forecastle starts contacting at diagonal brace $\left(\mathrm{LD}_{1}\right)$ and column $\left(\mathrm{L}_{4}\right)$. Figure $27(\mathrm{~b})$ shows the energy absorbed by the column and brace members along with the bow structure. It can be found that a significant amount of energy is also absorbed by the bow structure, mainly in the forecastle portion. Thus the brace members are predominantly exposed to damage from the forecastle, which is a comparatively larger size than the bulb portion.

(a)

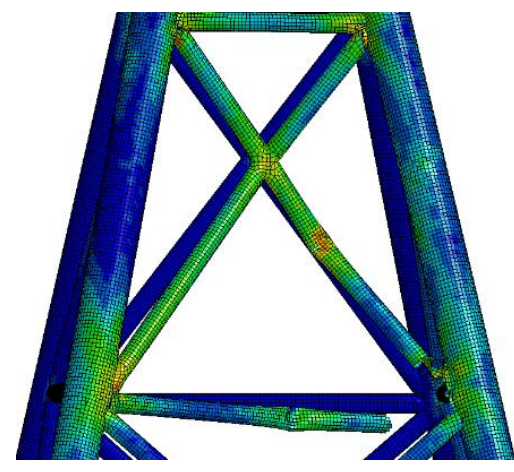

(b)

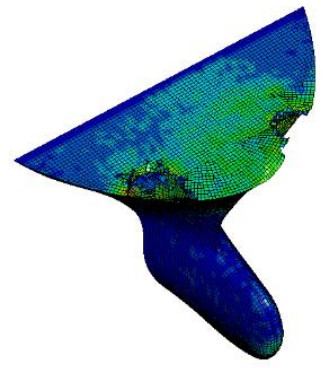

Fig. 27 Stress contour diagrams of bow impacting at collision velocity of $4 \mathrm{~m} / \mathrm{s}$ : (a) jacket platform, (b) bow structure. 


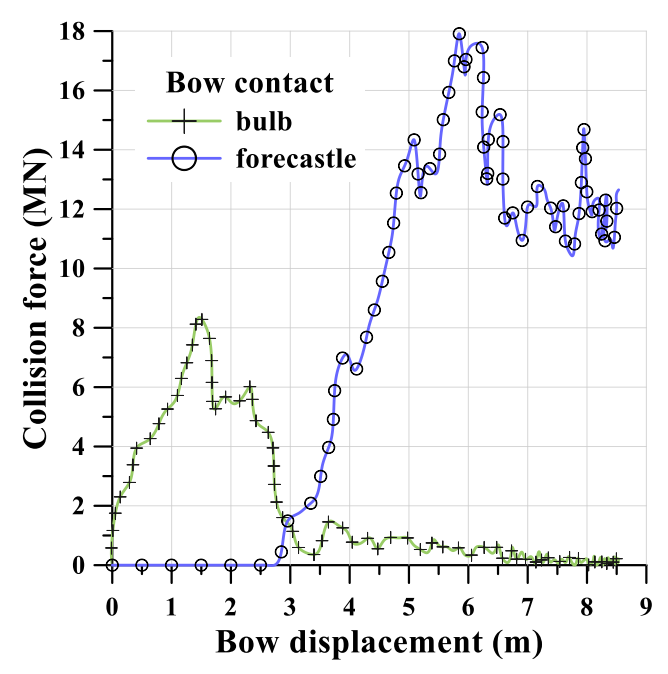

(a)

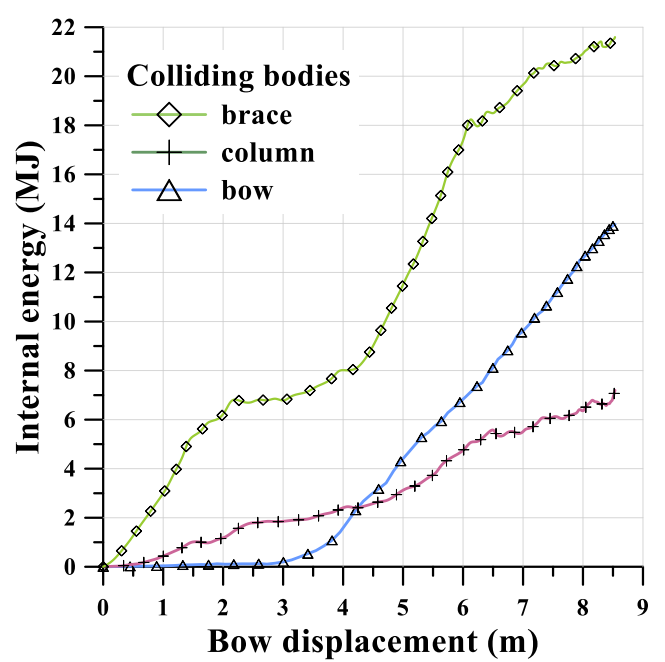

(b)

Fig. 28 Force and energy plots for bow impact at brace members and a collision velocity of $4 \mathrm{~m} / \mathrm{s}$.

Figure 29(a) shows an example of a collision scenario where the OSV bow structure impacts a rigid column member at a speed of $3 \mathrm{~m} / \mathrm{s}$. As the bow projects outwardly more than the forecastle and the column have a batter of $1 / 7$, it is highly likely that the bulb imparts maximum damage to the column structure than the weaker forecastle, provided the vertical motion of OSV remains same during a collision. Moreover, the scantling properties and configurations make the bulb part stronger than the forecastle. This is illustrated in Fig. 29(b), where the bow portion experiences a maximum collision force during the entire collision period, and forecastle contact comes into play after the bow displacement of $3.3 \mathrm{~m}$. Thus the column members are largely damaged due to stiffer bulb than the forecastle.

(a)

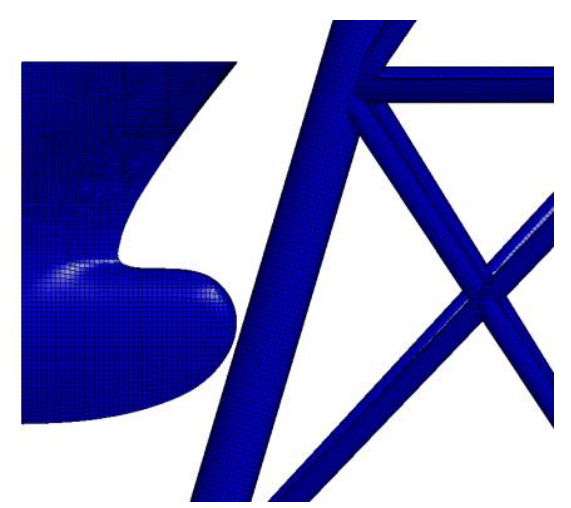

(b)

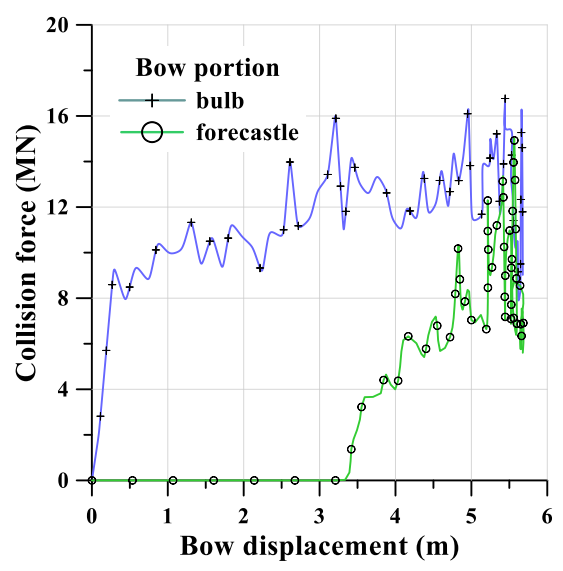

Fig. 29 Force-deformation curves for bulb and forecastle section of bow structure to a rigid column member $\left(\mathrm{L}_{5}\right)$. 
As shown in Fig. 23, the total impact energy of the bow during a collision is dissipated in both column and brace members. Figure 30 shows the results of maximum absorbed energy by column and brace members for different impact velocities and locations. It can be found that in general, among all scenarios, brace members absorbed the maximum amount of collision energy as compared to columns. This may be due to the low strength of the brace relative to column members. Further, brace joint collision scenarios consume maximum absorbed energy among all scenarios, followed by brace impact. This difference becomes more pronounced with an increase in impact velocity. Thus the design of brace members is the most critical part against ship collision.
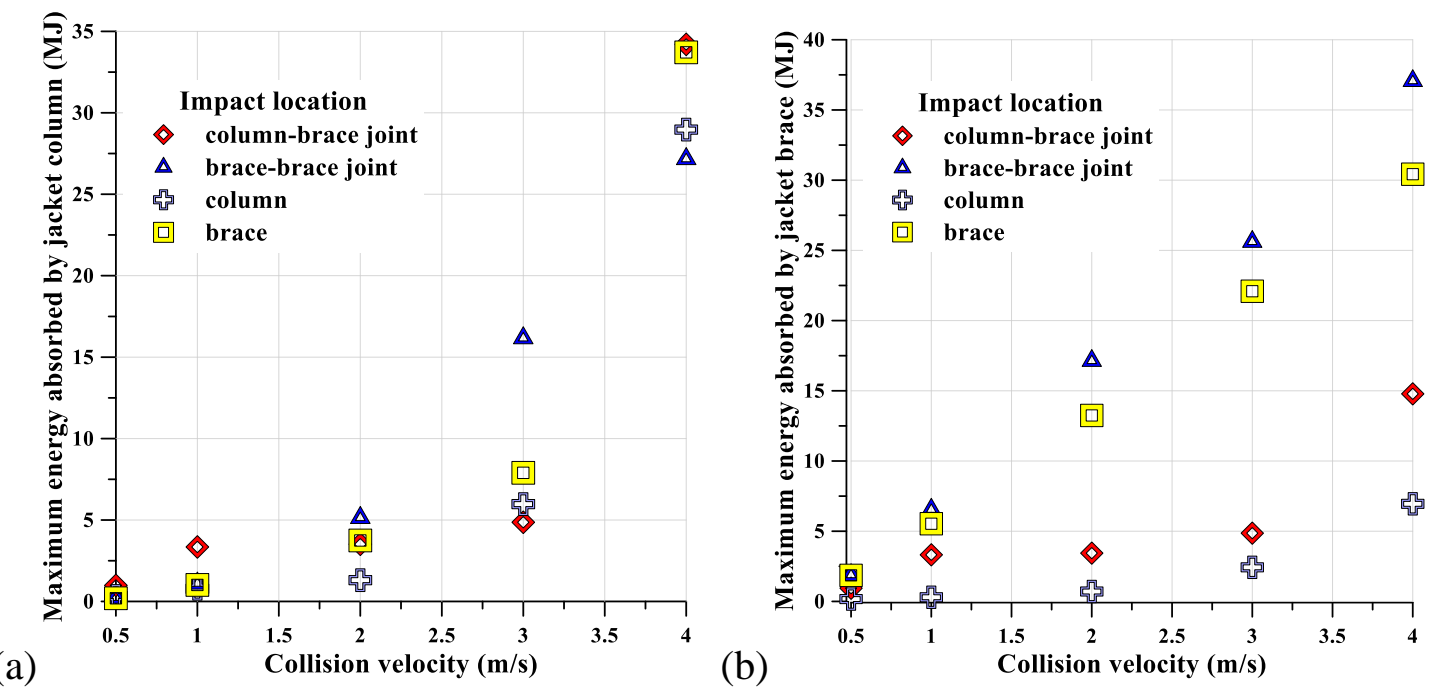

Fig. 30 Maximum absorbed energy for different collision velocities and impact locations: (a) column, (b) brace.

\section{Concluding remarks}

The study developed computational models for performing structural crashworthiness of collisions between a fixed-type offshore platform and an offshore supply vessel (OSV) using the nonlinear explicit finite element code, LS-DYNA. Particular emphasis was given to the material properties for the different materials involved in the various structural components. The study considered collisions between a jacket-type offshore platform and an OSV and performed a sensitivity analysis of the impact velocities and impact locations, etc. Based on the studies, the following conclusions can be drawn.

1. For supersized structures such as ships and offshore structures, a mesh convergence study for nonlinar finite element method modelling is usually costly, and thus simplified analytical equations and guidances could be used to define optimum mesh size.

2. The dynamic fracture strain depends on the relative stiffness of the OSV's bow and tubular jacket members as well as collision scenarios. Therefore, it should be defined separately for each of the interacting members in a collision scenario. 
3. The hydrodynamic effects due to the surrounding water increase peak load due to added mass, causing significant damage to the platform.

4. To investigate the extent of damage accurately, besides external contact, the internal contacts among structural components needs to be accounted for in the model.

5. The present numerical model predicts closely to the theoretical model of Wierzbicki and Suh [67] in minor collisions; however, conservative for the energy absorbed in the tubular members.

6. For the OSV's bow structure, a strength-based design is favourable for 'softer' forecastle section and ductile-based design for relatively 'stronger' bulb section. Using the same design methodology for a collision scenario may become erroneous and should be chosen separately based on the relative stiffness of colliding structures as well as collision scenario.

7. Majority of collisions scenarios shows that both forecastle and bulb section of OSV's bow structure contributes to the absorbed energy, where the vessel hit at multiple braces and column members. Therefore, a full-scale model of a jacket platform and OSV's bow structure is essential for numerical analysis to investigate load distributions among tubular members. Use of simplified analytical methods or small-scale physical model test database on a single brace or column member may prove conservative.

8. Further research includes the application of developed models for other types of collision scenarios, e.g., stern and sideways collision of OSV to the platform. Also, one may conduct the study for actual jacket platform considering increased stiffness at member's joint, fenders and boat landing structures and real environmental conditions.

9. The numerical modelling techniques developed in this study will be useful for quantitative risk assessment of fixed-type offshore structures colliding with an OSV.

\section{Acknowledgments}

This work was supported by a 2-Year Research Grant of Pusan National University.

\section{ORCID}

Jeom Kee Paik: http://orcid.org/0000-0003-2956-9359

\section{References}

[1] J.K. Paik, Advanced structural safety studies with extreme conditions and accidents, Springer, Singapore, 2019.

[2] M.P. Mujeeb-Ahmed, J.K. Paik, A probabilistic approach to determine design loads for collision between an offshore supply vessel and offshore installations, 
Ocean Eng. 173 (2019) 358-374.

[3] Bentley, Structural integrity assessment of a ship-impacted wellhead platform, (2017).https://www.bentley.com/en/project-profiles/zakum_development_comp any_wellhead_platform (accessed April 28, 2019).

[4] PSA, Investigation of Big Orange XVIII's collision with Ekofisk 2/4-W, The Petroleum Safety Authority Norway, 2009.

[5] S. Zhang, P.T. Pedersen, H. Ocakli, Collisions damage assessment of ships and jack-up rigs, Ships Offshore Struct. 10(5) (2015) 470-478.

[6] J.K. Paik, Ultimate Limit State Analysis and Design of Plated Structures, 2nd ed., Chcishester, UK, 2018.

[7] DNV GL, Recommended Practice, DNVGL-RP-C204, Design Against Accidental Loads, Høvik, Norway, 2017.

[8] M. Storheim, J. Amdahl, Design of offshore structures against accidental ship collisions, Mar. Struct. 37 (2014) 135-172.

[9] DNV GL AS, Class Guideline, DNVGL-CG-0127, Finite Element Analysis, Høvik, Norway, 2015.

[10] DNV GL AS, Recommended Practice, DNVGL-RP-C208, Determination of Structural Capacity by Non-linear FE analysis Methods, Høvik, Norway, 2016.

[11] J.W. Ringsberg, J. Amdahl, B.Q. Chen, S.R. Cho, S. Ehlers, Z. Hu, J.M. Kubiczek, M. Kõrgesaar, B. Liu, J.N. Marinatos, K. Niklas, J. Parunov, B.W.T. Quinton, S. Rudan, M. Samuelides, C.G. Soares, K. Tabri, R. Villavicencio, Y. Yamada, Z. Yu, S. Zhang, MARSTRUCT benchmark study on nonlinear FE simulation of an experiment of an indenter impact with a ship side-shell structure, Mar. Struct. 59 (2018) 142-157.

[12] J. Travanca, H. Hao, Energy dissipation in high-energy ship-offshore jacket platform collisions, Mar. Struct. 40 (2015) 1-37.

[13] J. Travanca, H. Hao, Numerical analysis of steel tubular member response to ship bow impacts, Int. J. Impact Eng. 64 (2014) 101-121.

[14] Z. Yu, J. Amdahl, Analysis and design of offshore tubular members against ship impacts, Mar. Struct. 58 (2018) 109-135.

[15] Z. Yu, A review of structural responses and design of offshore tubular structures subjected to ship impacts, Ocean Eng. 154 (2018) 177-203.

[16] G. Notaro, A. Johansen, S.M. Selås, T. Nybø, Estimation of high energy collision response for jacket structures, Proc. ASME 2015 34th Int. Conf. Ocean. Offshore Arct. Eng. OMAE2015, May 31-June 5, 2015, St. John's, Newfoundland, Canada. (2015) 1-10.

[17] J.O. Hallquist, LS-DYNA keyword user's manual, Livermore Softw. Technol. 
Corp. 970 (2007) 299-800.

[18] J.K. Paik, Computational Models for Offshore Structural Load Analysis in Collisions, in: Adv. Struct. Saf. Stud. With Extrem. Cond. Accid., Springer, Singapore, 2019: pp. 145-187.

[19] API, Recommended Practice for Planning, Designing, and Constructing Fixed Offshore Platforms 2A, 9th ed., American Petroleum Institute, Washington, DC, 1977.

[20] DNV GL AS, 2015-0984, FE Model Library for Collision Analysis: Description and Results, Høvik, Norway, 2016.

[21] M.P. Mujeeb-Ahmed, J.K. Seo, J.K. Paik, Probabilistic approach for collision risk analysis of powered vessel with offshore platforms, Ocean Eng. 151 (2018) 206-221.

[22] H. Le Sourne, A. Barrera, J.B. Maliakel, Numerical crashworthiness analysis of an offshore wind turbine jacket impacted by a ship, J. Mar. Sci. Technol. 23 (5) (2015) 694-704.

[23] T. Belytschko, J.I. Lin, T. Chen-Shyh, Explicit algorithms for the nonlinear dynamics of shells, Comput. Methods Appl. Mech. Eng. 42 (1984) 225-2251.

[24] T. Wierzbicki, W. Abramowicz, On the crushing mechanics of thin-walled structures, J. Appl. Mech. 50 (1983) 727-734.

[25] API, Recommended Practice 2A-WSD: Planning, Designing and Constructing Fixed Offshore Platforms - Working Stress Design, 22nd ed., American Petroleum Institute, Washington, DC, 2014.

[26] J.K. Paik, A.K. Thayamballi, Some recent developments on ultimate limit state design technology for ships and offshore structures, Ships Offshore Struct. 1 (2006) 99-116.

[27] J.K. Paik, K.J. Kim, J.H. Lee, B.G. Jung, S.J. Kim, Test database of the mechanical properties of mild, high-tensile and stainless steel and aluminium alloy associated with cold temperatures and strain rates, Ships Offshore Struct. 12 (2017) S230-S256.

[28] M. Storheim, J. Amdahl, On the sensitivity to work hardening and strain- rate effects in nonlinear FEM analysis of ship collisions collisions, Ships Offshore Struct. 12(1) (2017) 100-115.

[29] S.T. Ince, A. Kumar, J.K. Paik, A new constitutive equation on ice materials, Ships Offshore Struct. 12 (2017) 610-623.

[30] N. Jones, Structural impact, 2nd ed., Cambridge University Press, New York, USA, 2012.

[31] K. Liu, B. Liu, R. Villavicencio, Z. Wang, C. Guedes Soares, Assessment of 
material strain rate effects on square steel plates under lateral dynamic impact loads, Ships Offshore Struct. 13 (2018) 217-225.

[32] HSE, Ship collision and capacity of brace members of fixed steel offshore platforms, Health and Safety Executive, U.K., 2004.

[33] Y.G. Ko, S.J. Kim, J.M. Sohn, J.K. Paik, A practical method to determine the dynamic fracture strain for the nonlinear finite element analysis of structural crashworthiness in ship-ship collisions, Ships Offshore Struct. 13(14) (2018) $412-422$.

[34] G.R. Cowper, P.S. Symonds, Strain-hardening and strain-rate effects in the impact loading of cantilever beams, Division of applied mathematics. Brown university, 1957.

[35] R. Tørnqvist, Design of crashworthy ship structures, 2003.

[36] H.S. Alsos, O.S. Hopperstad, R. Törnqvist, J. Amdahl, Analytical and numerical analysis of sheet metal instability using a stress based criterion, Int. J. Solids Sructures. 45 (2008) 2042-2055.

[37] J.R. Davis, Tensile Testing, 2nd ed., Materials Park, Ohio, USA, 2004.

[38] M. Storheim, J. Amdahl, I. Martens, On the accuracy of fracture estimation in collision analysis of ship and offshore structures, Mar. Struct. 44 (2015) 254287.

[39] M.A.G. Calle, M. Alves, A review-analysis on material failure modeling in ship collision, Ocean Eng. 106 (2015) 20-38.

[40] S.J. Park, K. Lee, B.C. Cerik, J. Choung, Ductile fracture prediction of EH36 grade steel based on Hosford-Coulomb model, Ships Offshore Struct. 14 (2019) 219-230.

[41] DNV, Recommended Practice DNV-RP-C204, Design against Accidental Loads, Høvik, Norway., 2010.

[42] J.K. Paik, Practical techniques for finite element modeling to simulate structural crashworthiness in ship collisions and grounding (Part I: Theory), Ships Offshore Struct. 2:1 (2007) 69-80.

[43] N. Jones, On the dynamic inelastic failure of beams, in: T. Wierzbicki, N. Jones (Eds.), Struct. Fail., John Wiley, 1989: pp. 133-159.

[44] O.F. Hughes, J.K. Paik, D. Béghin, J.B. Caldwell, H.G. Payer, T.E. Schellin, Ship structural analysis and design, The Society of Naval Architects and Marine Engineers, Jersey City, 2010.

[45] J.K. Paik, A.K. Thayamballi, Ship-Shaped Offshore Installations: Design, Building, and Operation, Cambridge University Press, New York, USA, 2007.

[46] I. Pill, K. Tabri, Finite element simulations of ship collisions: a coupled 
approach to external dynamics and inner mechanics, Ships Offshore Struct. 6:1-2 (2011) 59-66.

[47] K. Tabri, Influence of coupling in the prediction of ship collision damage, Ships Offshore Struct. 7(1) (2012) 47-54.

[48] M. Ferry, H. Le Sourne, F. Besnier, 02/RT016: MCOL Theoretical Manual, Principia Tech. Rep. (2002) 1-18.

[49] M. Ferry, H. Le Sourne, F. Besnier, 02/RT017: MCOL User's Manual, Principia Tech. Rep. (2002) 1-15.

[50] Y.G. Ko, S.J. Kim, J.K. Paik, Effects of a deformable striking ship's bow on the structural crashworthiness in ship-ship collisions, Ships Offshore Struct. 13:sup1 (2018) 228-250.

[51] Y.S. Kim, S. Youssef, S. Ince, S.J. Kim, J.K. Seo, B.J. Kim, Y.C. Ha, J.K. Paik, Environmental consequences associated with collisions involving double hull oil tanker, Ships Offshore Struct. 10:5 (2015) 479-487.

[52] S.A.M. Youssef, S.T. Ince, Quantitative risk assessment for collisions involving double hull oil tankers, Trans. R. Inst. Nav. Archit. Part A Int. J. Marit. Eng. 156 (2014) 157-174.

[53] H. Le Sourne, N. Besnard, C. Cheylan, N. Buannic, A Ship Collision Analysis Program Based on Upper Bound Solutions and Coupled with a Large Rotational Ship Movement Analysis Tool, J. Appl. Math. 2012 (2012) 1-27.

[54] H. Le Sourne, N. Couty, F. Besnier, C. Kammerer, H. Legavre, LS-DYNA Applications in Shipbuilding, in: 4th Eur. LS-DYNA Users Conf., Ulm, Germany, 2003: p. A-II-01-A-II-16.

[55] H. Le Sourne, R. Donner, F. Besnier, M. Ferry, External Dynamics of Ship-Submarine Collision, in: 2nd Int. Conf. Collis. Grounding Ships, Copenhagen, 2001: pp. 137-144.

[56] P.T. Pedersen, S. Zhang, On impact mechanics in ship collisions, Mar. Struct. 11(10) (1999) 429-449.

[57] J.K. Paik, Computational Models for Structural Crashworthiness Analysis in Collisions and Grounding, in: Adv. Struct. Saf. Stud. With Extrem. Cond. Accid., Springer, Singapore, 2019: pp. 279-311.

[58] L. Zhu, Q. Liu, M. Chen, Experimental study on the deformation of fully clamped pipes under lateral impact, Int. J. Impact Eng. 111 (2018) 94-105.

[59] J. de Oliveira, T. Wierzbicki, W. Abramowicz, Norske Veritas, Plastic behaviour of tubular members under lateral concentrated loading, Det Nor. Verit. 47 (1982).

[60] C.P. Ellinas, A.C. Walker, Damage on offshore tubular bracing members, 
IABSE. (1983) 253-261.

[61] B.C. Cerik, H.K. Shin, S.R. Cho, A comparative study on damage assessment of tubular members subjected to mass impact, Mar. Struct. 46 (2016) 1-29.

[62] NORSOK, Design of steel structures: N-004, Lysaker, Norway, 2004.

[63] O. Furnes, J. Amdahl, Ship collisions with offshore platforms, in: Intermaritec, Hamburg, Germany, 1980: pp. 310-318.

[64] API, Recommended Practice for Planning, Designing and Constructing Fixed Offshore Platforms-Working Stress Design, 21st ed., American Petroleum Institute, Washington, DC, 2002.

[65] DNV, Design Against Accidental Loads, Recomm. Pract. DNV-RP-C204. (2010) 7-52.

[66] S. Cho, J. Kwon, D. Kwak, Structural characteristics of damaged offshore tubular members, Ocean Eng. Technol. 24 (2010) 1-7.

[67] T. Wierzbicki, M.S. Suh, Indentation of tubes under combined loading, Int. J. Mech. Sci. 30 (1988) 229-248. 